\title{
Dual Mechanism for Bitter Avoidance in Drosophila
}

\author{
Alice Sarah French, ${ }^{1,2,7 *}$ Marie-Jeanne Sellier, ${ }^{1,2 *}$ Moutaz Ali Agha, ${ }^{1,7}$ Alexandra Guigue, ${ }^{1,2} \odot$ Marie-Ange Chabaud, ${ }^{1 *}$ \\ -Pablo D. Reeb, ${ }^{3}$ Aniruddha Mitra, ${ }^{7}$ Yves Grau, ${ }^{4,5,6}$ - Laurent Soustelle,,${ }^{4,5,6}$ and ${ }^{-F}$ Frédéric Marion-Poll ${ }^{1,2,7}$ \\ ${ }^{1}$ Institut National de la Recherche Agronomique, Unité Mixte de Recherche (UMR) Institut d'Ecologie et des Sciences de l'Environnement de Paris, F-78026 \\ Versailles, France, ${ }^{2}$ AgroParisTech, Département Sciences de la Vie et Santé, F-75231 Paris, France, ${ }^{3}$ Universidad Nacional del Comahue, Facultad de \\ Ciencias Agrarias, Departamento de Estadistica, RA-8303 Cinco Saltos, Argentina, ${ }^{4}$ Centre National de la Recherche Scientifique (CNRS), UMR 5203, \\ Institut de Génomique Fonctionnelle, F-34094 Montpellier, France, 5Institut National de la Santé et de la Recherche Médicale, U661, F-34094 Montpellier, \\ France, ${ }^{6}$ Universités de Montpellier 1 and 2, UMR 5203, F-34094 Montpellier, France, and ${ }^{7}$ CNRS, Unité mixte de Recherches UMR 9191 , Evolution, \\ Génomes, Comportement, Ecologie F-91198 Gif-sur-Yvette, France
}

In flies and humans, bitter chemicals are known to inhibit sugar detection, but the adaptive role of this inhibition is often overlooked. At best, this inhibition is described as contributing to the rejection of potentially toxic food, but no studies have addressed the relative importance of the direct pathway that involves activating bitter-sensitive cells versus the indirect pathway represented by the inhibition of sugar detection. Using toxins to selectively ablate or inactivate populations of bitter-sensitive cells, we assessed the behavioral responses of flies to sucrose mixed with strychnine (which activates bitter-sensitive cells and inhibits sugar detection) or with L-canavanine (which only activates bitter-sensitive cells). As expected, flies with ablated bitter-sensitive cells failed to detect L-canavanine mixed with sucrose in three different feeding assays (proboscis extension responses, capillary feeding, and two-choice assays). However, such flies were still able to avoid strychnine mixed with sucrose. By means of electrophysiological recordings, we established that bitter molecules differ in their potency to inhibit sucrose detection and that sugar-sensing inhibition affects taste cells on the proboscis and the legs. The optogenetic response of sugar-sensitive cells was not reduced by strychnine, thus suggesting that this inhibition is linked directly to sugar transduction. We postulate that sugar-sensing inhibition represents a mechanism in insects to prevent ingesting harmful substances occurring within mixtures.

Key words: behavior; bitter; Drosophila; electrophysiology; mixture interaction; sweet

\section{Introduction}

Animals, including insects, detect a number of chemicals as aversive via specialized taste cells (Yarmolinsky et al., 2009). These aversive chemicals define a sensory space usually described as "bitter" by analogy with human sensation. Bitter taste is thought to contribute to protecting animals against ingesting potentially toxic molecules (Glendinning, 2002, 2007). Accordingly, omniv-

Received April 1, 2014; revised Jan. 16, 2015; accepted Jan. 24, 2015.

Author contributions: A.S.F., M.-J.S., M.A.A., A.G., M.-A.C., A.M.,Y.G., L.S., and F.M.-P. designed research; A.S.F., M.-J.S., M.A.A., A.G., M.-A.C., A.M., Y.G., and L.S. performed research; F.M.-P. contributed unpublished reagents/ analytictools; A.S.F.,M.-J.S., M.A.A., A.G., M.-A.C.,P.R., A.M.,Y.G., L.S., and F.M.-P. analyzed data;A.S.F. and F.M.-P. wrote the paper.

*A.S.F. and M.-J.S. contributed equally to the work.

The authors declare no competing financial interests.

This work was supported by French National Research Agency projects INSAVEL (Integrative Study of Insect Aversive Learning; M.-J.S., M.-A.C. and F.M.-P.), ADAPTANTHROP (Adaptation of insects to anthroposystems; A.G.), and DESIRABLE (Designing the Insect Biorefinery to Contribute to a More Sustainable Agrifood Industry; M.A.A.), grants from ABIES (Doctoral School Agriculture, Nutrition, Environment and Health; A.S.F., M.-J.S.), INRA (National Institute of Agronomic Research; M.-J.S.), the Syrian government (M.A.A.), and a Marie Curie Grant TASTEVOL (The taste of volatiles - International Incoming Fellowship PIIF-GA-2012-330101; A.M.). We thank Kristin Scott, John Carlson, Craig Montell, and Teiichi Tanimura for the strains used in this work. We acknowledge insights provided by readers of previous versions of this manuscript: John Carlson, Anupama Dahanukar, and Haruhiko Itagaki. We also thank two anonymous reviewers for helping us to improve our manuscript.

Correspondence should be addressed to Frédéric Marion-Poll, Centre National de la Recherche Scientifique, Unité Propre de Recherche 9034, Laboratoire Génomes, Evolution et Spéciation, F-91198 Gif-sur-Yvette, France. E-mail: frederic.marion-poll@legs.cnrs-gif.fr.

DOI:10.1523/JNEUROSCI.1312-14.2015

Copyright $\odot 2015$ the authors $\quad 0270-6474 / 15 / 353990-15 \$ 15.00 / 0$ orous/polyphagous animals possess a large panel of bitter taste receptors, whereas animals specialized on a restricted diet have few, because they are potentially exposed to a lesser variety of toxic molecules. This rule has been observed in vertebrates (Wooding, 2005; Dong et al., 2009; Jiang et al., 2012; Hong and Zhao, 2014; Li and Zhang, 2014) and insects (McBride and Arguello, 2007; Richards et al., 2008; Kirkness et al., 2010), with a few exceptions (Wanner and Robertson, 2008; Engsontia et al., 2014). Animals, including insects, also possess "sweet" receptors expressed in specific taste cells that detect molecules triggering food acceptance (Zhao et al., 2003; Chandrashekar et al., 2006; Yarmolinsky et al., 2009). These two populations of taste cells that sense either sugar or bitter chemicals directly trigger feeding or aversion if activated (Marella et al., 2006; Hiroi et al., 2008; Gordon and Scott, 2009), whereas disrupting one of them impairs the corresponding behavior (Wang et al., 2004). This suggests that taste is encoded by labeled lines and supports the view that the final decision is taken after the brain has weighed information from these two lines (Masek and Scott, 2010).

However, each taste modality is not insensitive to stimuli from other modalities. For example, bitter chemicals inhibit sugar detection in insects of different groups (Morita, 1959; Dethier, 1980, 1987; Schoonhoven, 1982; Dethier and Bowdan, 1989, 1992; Chapman et al., 1991; Schoonhoven and Liner, 1994), including Drosophila (Meunier et al., 2003a; Lee et al., 
Table 1.

\begin{tabular}{llll}
\hline Fly strain & Short-hand name & Significance to the study & Source \\
\hline White & W $^{\text {1118 }}$ & Reference strain carrying the mutation white & K. Scott \\
& Gr66a-Gal4 & Driver for cells expressing Gr66a (bitter-sensitive) & K. Scott (Wang et al., 2004) \\
& Gr64f-Gal4 & Driver for cells expressing Gr64f (sugar-sensitive) & J. Carlson (Dahanukar et al., 2007) \\
& Gr33a-Gal4 & Driver for cells expressing Gr33a (bitter-sensitive) & J. Carlson \\
& UAS-DTI & Reporter expressing DTI to kill cells & K. Scott (Wang et al., 2004) \\
W $^{*} ;$ P[UAS-TeTxLC.tnt]R3 & UAS-TeTxLC & Reporter expressing TeTxLC to inactivates synaptic transmission & Bloomington Drosophila Stock Center strain BL 28997 \\
W $^{*} ;$ P[UAS-H134R-ChR2]2 & UAS-ChR2 & Reporter expressing a channel rhodopsin to activate neurons with light & Bloomington Drosophila Stock Center strain BL 28995 \\
Gr66a-Gal4/UAS-ChR2 & Gr66a $>$ ChR2 & Express ChR2 into Gr66a cells & \\
Gr64f-Gal4/UAS-ChR2 & Gr64f>ChR2 & Express ChR2 into Gr64f cells & \\
Gr66a-Gal4/+;UAS-DTI/+ & Gr66a $>$ DTI & Express DTI into Gr66a cells to kill them & \\
Gr66a-Gal4/+;UAS-TeTxLC/+ & Gr66a $>$ TeTxLC & Express the TeTxLC into Gr66a cells to inactivate their synaptic & \\
& & transmission & \\
\hline
\end{tabular}

2010, 2012; Sellier and Marion-Poll, 2011; Jeong et al., 2013) in which other interactions were described recently, such as between sugars and acids (Charlu et al., 2013; Chen and Amrein, 2014). Whereas the molecular basis of bitter suppression of sugar detection is still under scrutiny and may involve odorant binding proteins (OBPs; Jeong et al., 2013; Swarup et al., 2014), the behavioral role of such interactions have been considered rarely (König et al., 2014).

We examined here to what extent bitter suppression of sugar detection influences behavioral choices in adult Drosophila. We demonstrate that the activation of bitter-sensitive cells does not suffice to inhibit proboscis extension responses (PERs) and that complete inhibition of the PER requires shutting off the signal conveyed by sugar-sensitive cells. Using behavior and optogenetics, we show that the simultaneous activation of bitter-sensitive cells along with the inhibition of sugar detection is necessary to elaborate a proper response to ambiguous mixtures of tastants. We further show that sugar-sensitive cell inhibition is a specific property of sugar transduction. We postulate that sugar-sensing inhibition complements canonical bitter detection to prevent the ingestion of harmful substances when mixed with beneficial substances.

\section{Materials and Methods}

Chemicals. Sucrose, KCl, L-canavanine, caffeine, lobeline, escin, nicotine, strychnine, denatonium, tricholine citrate (TCC), erioglaucine, sulforhodamine B, and all trans-retinal were from Sigma-Aldrich. Brilliant blue FCF was from Tokyo Kasei.

Flies. Flies were maintained on a standard cornmeal agar medium at $25^{\circ} \mathrm{C}$ and $80 \%$ humidity on a $12 \mathrm{~h} \mathrm{light/dark} \mathrm{cycle.} \mathrm{Unless} \mathrm{notified} \mathrm{oth-}$ erwise, we used 2- to 5-d-old adults. Insects subjected to behavioral tests were starved for $24 \mathrm{~h}$ before the experiment.

To manipulate specific populations of taste cells, we used the UASGal4 system (Brand and Perrimon, 1993). Bitter-sensitive cells were targeted using Gr66a-Gal4 (Wang et al., 2004). Sugar-sensitive cells were addressed with Gr64f-Gal4 (Dahanukar et al., 2007). We crossed these flies with flies carrying a secondary transgene activated by GAL4 in the progeny. As a secondary transgene, we used a diphtheria toxin (UASDTI; Wang et al., 2004) to ablate cells expressing Gr66a in the progeny (called Gr66a $>$ DTI throughout text). We also used the tetanus toxin light chain (TeTxLC), which impairs neurotransmission at synapses by degrading synaptobrevin (Sweeney et al., 1995). In the progeny of Gr66a-Gal4 flies crossed with UAS-TeTxLC flies and Gr66a-Gal4/+; $U A S-T e T x L C /+$ flies (mentioned as Gr66a $>$ TeTxLC throughout text), bitter-sensitive neurons are inactive. To express a channel rhodopsin into taste neurons, UAS-ChR2 flies were crossed with flies carrying Gr66a-Gal4 (Wang et al., 2004) or Gr64f-Gal4] (Dahanukar et al., 2007). In the progeny (mentioned as Gr66a>ChR2 and Gr64f>ChR2 throughout text), blue light (BL) induces a spiking activity in the neurons expressing channelrhodopsin 2 (ChR2). These flies and the control strains were raised on medium supplemented with $1 \mathrm{~mm}$ all trans-retinal (Schroll et al., 2006; Hornstein et al., 2009) and kept in darkness.

$w^{1118}$, Gr66a-Gal4, and UAS-DTI strains were generously provided by Kristin Scott (University of California at Berkeley, CA) and Gr64f-Gal4 flies by John Carlson (Yale University, New Haven, CT). UAS-TeTxLC and UAS-ChR2 flies were obtained from the Bloomington Drosophila Stock Center (strains BL 28997 and BL 28995, respectively). A list of the flies used in this study is provided in Table 1. In all experiments, we compared flies carrying both transgenes (UAS and GAL4) to their parents carrying only one transgene and designed hereafter as control flies.

Proboscis responses (PER and proboscis retraction) after stimulation of labellar sensilla. To stimulate labellar taste sensilla, flies ( $1-5 \mathrm{~d}$ old) were prepared according to Shiraiwa and Carlson (2007). Before the experiment, flies were starved for $24 \mathrm{~h}$ by placing them into a vial with humid cotton. Flies were introduced into the cut ends of $200 \mu \mathrm{l}$ micropipette tips so that the head was protruding and the proboscis was free to move. Taste sensilla of the labellum were stimulated by gently touching the labellum during $2 \mathrm{~s}$ with the fine tapering end of a strip of filter paper, soaked with the test solution (Fig. 1A); if the fly extended its proboscis, the stimulus was removed immediately to prevent drinking. We scaled the PER of the fly as 1 if the proboscis was fully extended within $2 \mathrm{~s}$ after the contact and as 0 otherwise. We also monitored proboscis retraction (PR) and scaled it as 1 if the fly retracted the proboscis (and maintained retraction) within $5 \mathrm{~s}$ after having fully extended it and 0 otherwise (Fig. $1 \mathrm{~A}$; Dethier, 1980; Mitri et al., 2009).

We used this method to test whether ablating cells expressing Gr66a affects the responses to sugar mixed with strychnine or L-canavanine, which are both aversive for flies (Meunier et al., 2003a; Hiroi et al., 2004; Mitri et al., 2009; Sellier et al., 2011; Lee et al., 2012; Devambez et al., 2013). Strychnine is an alkaloid molecule, whereas $\mathrm{L}$-canavanine is a toxic nonprotein amino acid (Rosenthal, 2001; Kool, 2005). Both substances activate bitter-sensitive cells in Drosophila and do not activate other taste cells (Meunier et al., 2003a; Hiroi et al., 2004; Lee et al., 2012). Therefore, it is expected that flies deprived of their bitter-sensitive cells should become less sensitive to these substances. Furthermore, there should be a discrepancy between the effect of bitter-sensitive cell ablation on L-canavanine and strychnine avoidance given that the former does not strongly inhibit sugar-sensitive cells (Jeong et al., 2013).

The sequence of stimulation was water, sucrose, test solution (strychnine plus sucrose, L-canavanine plus sucrose, or sucrose alone), sucrose, and water, each separated by $2 \mathrm{~min}$. The responses to the test stimulus were recorded from only those flies that responded to the first sucrose presentation and that did not respond to water. The concentrations of chemicals used were $0.1 \mathrm{~m}$ sucrose, $10 \mathrm{~mm}$ strychnine plus $0.1 \mathrm{~m}$ sucrose, and $40 \mathrm{~mm}$ L-canavanine plus $0.1 \mathrm{~m}$ sucrose.

Proboscis responses (PER and PR) after stimulation of leg sensilla. To stimulate taste sensilla of the prothoracic legs, four to five flies (narcotized with ice) were disposed on a microscopic slide, placed on pads of adhesive clay (UHU yellow patafix), and restrained on their dorsum with fine strips of tape. They were left to recover from the manipulation at $25^{\circ} \mathrm{C}$ and $80 \%$ humidity for $2 \mathrm{~h}$. Before the experiment, flies were fed water to satiation, and their legs were washed with water. The legs were 
A

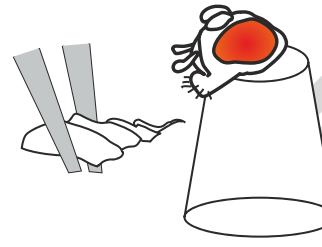

stimulation

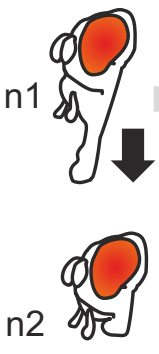

$\mathrm{PER}=$ $\mathrm{n} 1 /(\mathrm{n} 1+\mathrm{n} 2)$

B

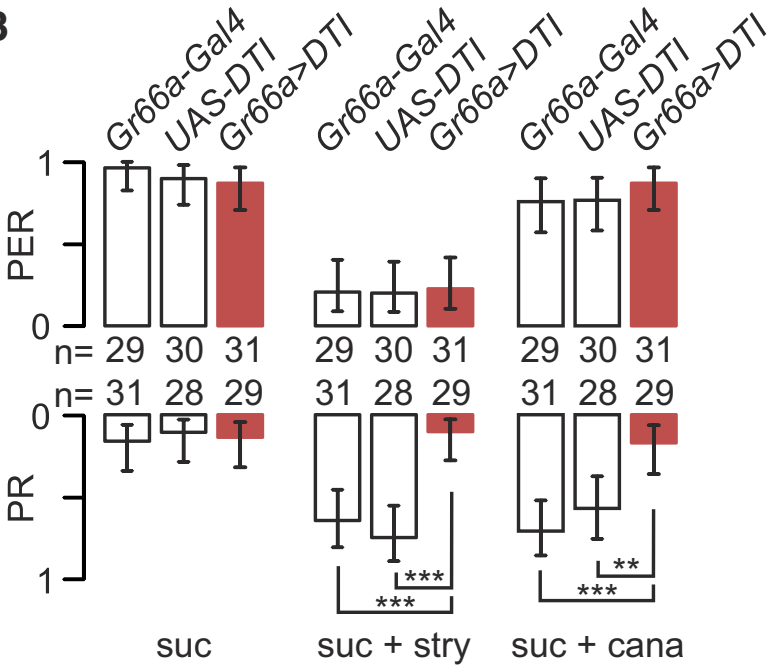

Figure 1. Strychnine-induced inhibition of the PER is not affected by the ablation of labellar taste neurons expressing Gr66a, whereas PR activation is reduced. $\boldsymbol{A}$, The proboscis of restrained flies was stimulated with a wick soaked with test solution for $5 \mathrm{~s}$. We monitored the number of flies extending their proboscis and the number of flies actively retracting their proboscis after having extended it within the $5 \mathrm{~s}$ observation period. $\boldsymbol{B}$, Bitter-sensitive cells were ablated in the progeny of flies carrying a diphtheria toxin (UAS-DTI) crossed with flies carrying Gr66a-Gal4. We compare the PER (top bars graph) and the PR (bottom bars graph) of flies with ablated bitter cells (Gr66a $>$ DTI, red bars) to control flies bearing only one of these constructions (Gr66a-Gal4 or UAS-DTI, white bars). Each fly was stimulated in sequence with $0.1 \mathrm{~m}$ sucrose (suc), $0.1 \mathrm{~m}$ sucrose plus $10 \mathrm{~mm}$ strychnine (suc + stry) or $0.1 \mathrm{~m}$ sucrose $+40 \mathrm{~mm}$ L-canavanine (suc + cana). The values are displayed as the frequency of flies that responded $\pm 95 \%$ binomial confidence intervals, and asterisks indicate the significance values from a Fisher's exact test when comparing strains $\left({ }^{*} p<0.05,{ }^{* *} p<0.01,{ }^{* * *} p<0.001\right)$. The respective number of flies tested is displayed as numbers between the two graphs.

stimulated by touching them gently for $5 \mathrm{~s}$ with a toothpick dipped previously into a test solution. If the solution applied was a mixture, only one leg was touched (Fig. 2A). If bitter and sugar solutions were applied separately, one leg was stimulated with sugar and the contralateral leg was stimulated with bitter (or with water; Fig. $2 A$ ). Flies that did not extend their proboscis in response to the first presentation of sucrose were discarded. PERs and PRs were noted as mentioned previously.

This method was used to evaluate whether the mode of presentation of the stimuli had an influence on PER/PR and whether ablating different populations of bitter-sensitive cells of Gr66a>DTI or Gr33a>DTI flies would affect the responses. The order of stimulation was water, sucrose, test, water, and sucrose, separated by $2 \mathrm{~min}$, at the same concentrations and with the same chemicals as in the previous experiment mentioned above.

PERs/PRs to concurrent optogenetic and chemical stimulations. We used a Chlamydomonas reinhardtii cation channel ChR2 (Nagel et al., 2003) to activate taste cells expressing the protein encoded by this gene. ChR2 channels are activated by light at a wave length of $488 \mathrm{~nm}$ (Schroll et al.,
2006). BL was delivered by a light fiber from a $480 \mathrm{~nm}$ light source LED (CoolLED pE-100; Scientifica) illuminating the whole animal. Flies expressing ChR2 into either bitter-sensitive cells (using Gr66a-Gal4) or sugar-sensitive cells (using Gr64f-Gal4) were tested to evaluate whether the optogenetic activation of one class of taste cells could be modulated by the chemical activation of the other class.

To evaluate the effect of activating bitter-sensitive cells (expressing Gr66a) on PERs/PRs to sucrose, we stimulated Gr66a $>$ ChR2 flies and their parental lines with $0.1 \mathrm{M}$ sucrose alone or concurrently with a spot of BL during $5 \mathrm{~s}$ (Fig. $3 A$ ). The order of stimulation was sucrose, water, test (sucrose or sucrose plus BL), water, and sucrose. To evaluate the effect of strychnine on the PERs/PRs to the optogenetic activation of sugarsensitive cells, we stimulated Gr64f>ChR2 flies with a spot of BL during $5 \mathrm{~s}$ and presented $10 \mathrm{~mm}$ strychnine concurrently (Fig. $3 B$ ). The order of stimulation was BL, BL plus water (control for tactile stimulation), test (BL or BL plus strychnine), water, and BL plus water. Gr64f $>C h R 2$ flies that did not respond to the first BL stimulation and to BL plus water were discarded. The control strains were unresponsive to BL.

Multiple choice capillary feeder test. Multiple choice capillary feeder (MultiCAFE) experiments were performed as in the study by Sellier et al. (2011). Female flies (1-2 d old) were fed fresh food for $1 \mathrm{~d}$ and then starved for $20-22 \mathrm{~h}$ in the presence of a disk of water-saturated filter paper. Groups of 20 flies were then introduced into a plastic box and given access to an array of capillaries ( $5 \mu \mathrm{l}, 32 \mathrm{~mm}$; Hirschmann Geräte) containing food solutions for $2 \mathrm{~h}$ (in the dark; $25^{\circ} \mathrm{C}, 70 \%$ humidity). The liquid level in each capillary was measured using NIH ImageJ (Rasband and Bright, 1995) from pictures taken just before and at the end of the experiment. To assess evaporation, an additional box containing no flies was prepared. This box was prepared and handled in a similar manner, and the average change in liquid level, corresponding to evaporation, was subtracted from consumption measurements obtained from boxes containing flies. This test was used to assess whether Gr66a>DTI and Gr66a $>$ TeTxLC flies are defective in the detection of different concentrations of strychnine and L-canavanine mixed with sucrose.

Two-choice feeding test. Flies (3-5 d old) were starved on watersaturated cotton for $24 \mathrm{~h}$ and then placed in groups of 100 on a 60-well microtiter plate (Dutscher) at $25^{\circ} \mathrm{C}$ for $2 \mathrm{~h}$ in the dark. Alternating wells contained either $1 \%$ agarose with $0.15 \mathrm{mg} / \mathrm{ml}$ erioglaucine dye (blue) and $5 \mathrm{~mm}$ sucrose (and $10 \mathrm{~mm}$ strychnine or $40 \mathrm{~mm}$ L-canavanine) or 0.2 $\mathrm{mg} / \mathrm{ml}$ sulforhodamine B dye (red) and $1 \mathrm{~mm}$ sucrose. After $2 \mathrm{~h}$, the flies were frozen and sorted according to abdomen color blue (B), red (R), or purple (P). A preference index (PI) for the blue solution was computed as $(\mathrm{N} \underline{B}+0.5 \mathrm{~N} \underline{\mathrm{P}}) /(\mathrm{N} \underline{\mathrm{B}}+\mathrm{N} \underline{\mathrm{P}}+\mathrm{N} \underline{\mathrm{R}})$ where $\mathrm{N}$ stands for the number of flies of each category. A PI value of 1 indicates complete preference for the 5 mu sucrose (blue) solution, whereas 0 indicates complete preference for the $1 \mathrm{~mm}$ sucrose (red) solution. To check that the food colors are not introducing a bias, the same experiment was performed after exchanging the colors. This test was used to evaluate whether Gr66a>TeTxLC flies are defective in the detection of sugar mixed with either $10 \mathrm{~mm}$ strychnine or $30 \mathrm{~mm} \mathrm{~L}$-canavanine.

Electrophysiological recordings from taste sensilla on the proboscis. Taste sensilla were recorded from the proboscis of 1- to 5-d-old female flies. Flies were immobilized with fine strips of tape on a pad of clay (UHU yellow patafix) to maintain the proboscis extended and to expose sensilla of the labellum. The fly's body was electrically connected to the ground through either a glass electrode containing $0.1 \mathrm{~mm} \mathrm{KCl}$ or a drop of electrocardiogram gel connected to a silver wire. Individual taste sensilla (15, s6, and i9; see Fig. 5B-E) were stimulated for $2 \mathrm{~s}$ with a capillary electrode containing the stimulus and an electrolyte. This electrolyte was either $1 \mathrm{~mm} \mathrm{KCl}$ or $30 \mathrm{~mm}$ TCC to inhibit the activity from the water cell (Wieczorek and Wolff, 1989). The recording electrode was connected to a taste-specific amplifier (Marion-Poll and van der Pers, 1996), further amplified 50-100 times, bandpass filtered at 10-2800 Hz (CyberAmp 320; Molecular Devices), and digitally sampled at $10 \mathrm{kHz}$ (DT9816; Data Translation) under the control of a custom program, dbWave. The intensity of the response was measured by counting the number of spikes occurring during the $1 \mathrm{~s}$ of each recording. Stimulations were separated by at least $1 \mathrm{~min}$. Spikes were not sorted by amplitude or shape, except noted otherwise, because extracellular recordings from taste receptors in 
A<smiles>CCCCCC1CCCC1c1cccn1C</smiles>

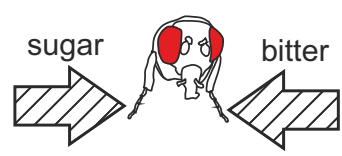

Dissociated

C

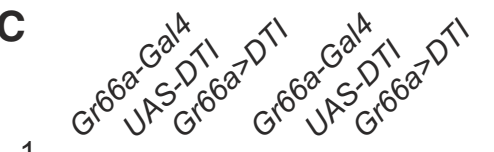

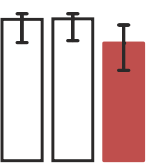

$\begin{array}{lll}26 & 28 & 30\end{array}$

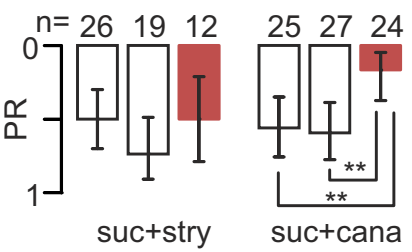

mixed

\section{E}
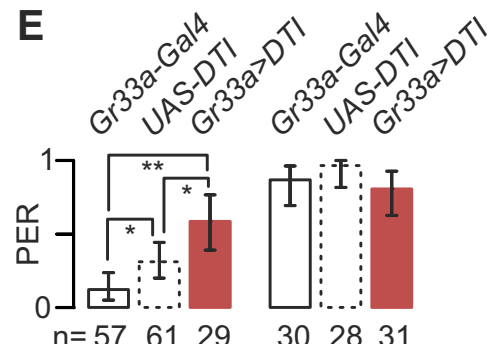

$\begin{array}{lll}30 & 28 & 31\end{array}$
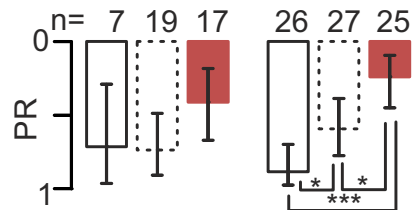

suc+stry

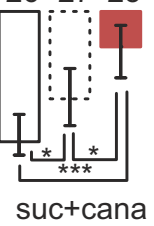

mixed

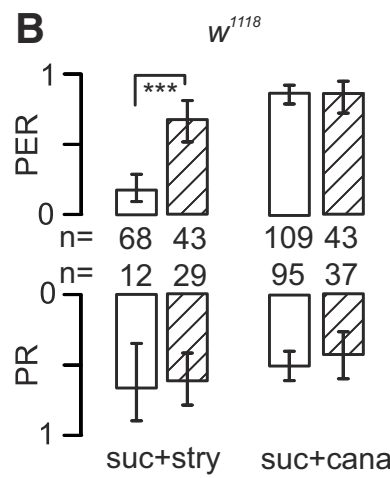

D
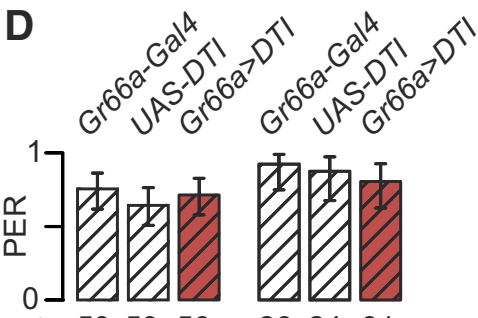

$\mathrm{n}=535956$

$\begin{array}{lll}26 & 24 & 31\end{array}$

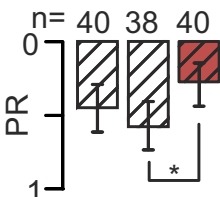

$\begin{array}{lll}24 & 21 & 25\end{array}$

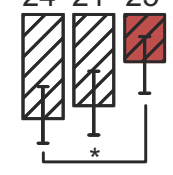

suc+stry

suc+cana dissociated

$F$
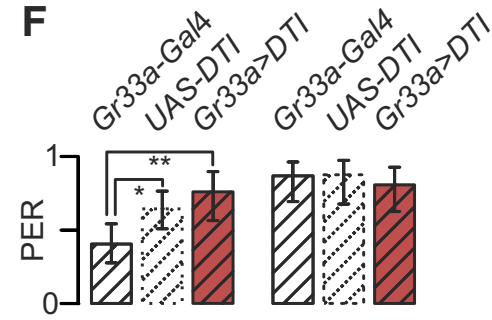

$\mathrm{n}=57 \quad 5929$

$30 \quad 2431$

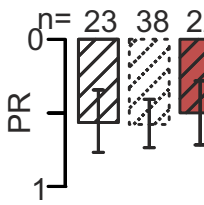

$\begin{array}{lll}26 & 21 & 25\end{array}$

suc+stry

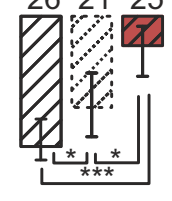

dissociated

Figure 2. Strychnine-induced inhibition of the PER on the legs is more potent in a mixture with sugar than when presented separately, and bitter-cell ablation reduces the PR. A, Flies were stimulated with $100 \mathrm{~mm}$ sucrose and a bitter chemical during $5 \mathrm{~s}$ by gently touching one leg with a mixture ("mixed" presentation) or each tarsus separately with sugar on one side and bitter on the other side ("dissociated" presentation). The bitter stimulus was $100 \mathrm{~mm}$ sucrose plus $10 \mathrm{~mm}$ strychnine (suc + stry) or $100 \mathrm{~mm}$ sucrose plus $40 \mathrm{~mm} \mathrm{~L}$-canavanine (suc + cana). $\boldsymbol{B}, \boldsymbol{w}^{1718}$ flies respond more strongly in the PER to the mixed (white bars) than to the dissociated stimuli (striped bars) for suc + stry $(p<0.001)$ but not to sucrose plus L-canavanine. PRs are not different with both stimuli. $\boldsymbol{C}, \boldsymbol{D}$, We ablated cells expressing Gr66a and recorded the responses to the same stimuli in Gr66a $>$ DTI flies (red bars) and in the parental strains that have intact taste cells (Gr66a-Gal4 and UAS-DTI). C, PERs/PRs to mixed presentation. D, PERs/PRs to dissociated presentation (striped bars) of the same stimuli. Note the higher PER to suc + stry in the dissociated presentation compared with the mixed stimulus. $\boldsymbol{E}, \boldsymbol{F}$, We also ablated cells expressing Gr33a and recorded the responses to these stimuli in Gr33a > DTI flies (red bars) and Gr33a-Gal4 flies (with intact taste cells). UAS-DTI flies were not tested again, but the previous values are reported on the graph for convenience. $\boldsymbol{E}$, PERs/PRs to the mixed presentation. $\boldsymbol{F}$, PERs/PRs to the dissociated stimuli. Graph legends, statistical tests, and abbreviations are the same as in Figure 1.

Drosophila are notoriously difficult to sort (Fujishiro et al., 1984; Meunier et al., 2003b).

Three separate experiments were performed. In the first (see Fig. $5 F-H$ ), we looked at the relative effectiveness of seven bitter chemicals on the responses of i9, 15 , and s6 sensilla to $0.1 \mathrm{M}$ sucrose mixed or not with $1 \mathrm{~mm}$ of a bitter chemical (nicotine, caffeine, escin, lobeline, strychnine, and denatonium) or $40 \mathrm{~mm}$ L-canavanine. In a second experiment (see Fig. $5 I-K)$, we looked at the effect of strychnine concentration $(0.001,0.1$, and $10 \mathrm{~mm})$ to inhibit the responses to $0.1 \mathrm{~m}$ sucrose in these sensilla.

In a third experiment (see Fig. 6), we recorded the spiking activity from $15, i 9$, and s6 sensilla in response to sucrose $(0.01,0.1$, and $1 \mathrm{M})$, strychnine $(0.001,0.1$, and $10 \mathrm{~mm})$, and $0.1 \mathrm{~m}$ sucrose mixed with strychnine $(0.001,0.1$, and $10 \mathrm{~mm})$ in Gr66a $>$ DTI flies and in their parental lines. Because i9 sensilla are not very sensitive to strychnine (Weiss et al., 2011), we also tested caffeine $(0.001,0.1$, and $10 \mathrm{~mm})$ to validate that the genetic construction is ablating the cell responding to bitter substances with the Gr66aGal4 driver.

Electrophysiological recordings from taste sensilla on the legs. Taste sensilla from the legs were recorded using the same procedures as when recording from labellar sensilla, except that one front leg was immobilized and properly oriented to allow tip recording. To verify that expression of DTI in Gr66a-expressing cells abolished responses to bitter tastants, the sensilla f5b and f5s (Ling et al., 2014), which differ in their expression of Gr66a (see Fig. 7B), were stimulated with $10 \mathrm{~mm}$ strychnine and $40 \mathrm{~mm}$ L-canavanine.

Electrophysiological recordings and optogenetic stimulation. To combine chemical and optogenetic activation of taste neurons, we used a modified tip-recording configuration. To control more strictly the timing of the chemical stimulation, we placed the head stage of the amplifier and the stimulus electrode on a sliding platform driven by a piezoelectric linear actuator (PPA10M and amplifier CA $\mu 10$; Cedrat Technologies). A light stimulator $(480 \mathrm{~nm}$ blue light; model pE-100; CoolLED) and the piezo actuator were driven by a programmable logic controller (RIO-47122; Galil).

To test whether the firing activity of bittersensitive cells could affect the responses to sugar, we recorded from i9 sensilla in Gr66a $>C h R 2$ flies; these sensilla host only two taste cells that elicit extracellular action potentials that are easy to sort (Hiroi et al., 2004). Each recording lasted $6 \mathrm{~s}$, during which three flashes of BL were delivered $(1,0.5$, and $0.5 \mathrm{~s}$ separated by $0.5 \mathrm{~s})$, starting $1 \mathrm{~s}$ after the beginning of the contact (see Fig. $8 A$ ). We displayed the time course of the responses within $100 \mathrm{~ms}$ bins.

To test whether strychnine inhibits the spiking generator within the sugar-sensitive cells or whether it interferes directly with sugar transduction, we recorded the responses to sugar or to optogenetic stimulation in the presence of strychnine in i9 and in 15/17 sensilla of Gr64f $>$ ChR2 flies. The recording configura- 


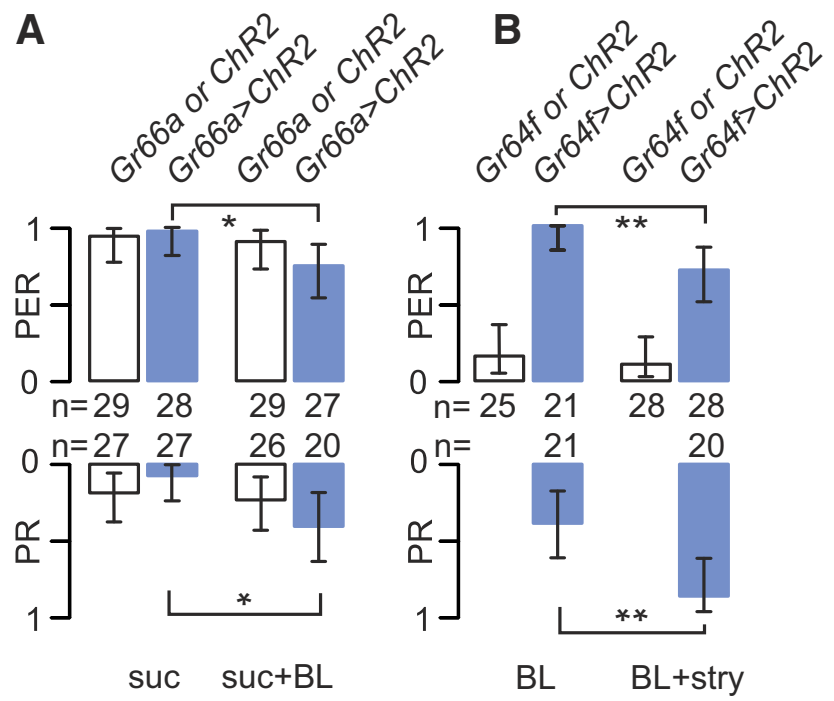

Figure 3. Optogenetic activation of either cell type bypasses the mixture effect. $A$, Flies expressing ChR2 in bitter-sensitive cells (Gr66a > ChR2) were stimulated on the tarsi with $0.1 \mathrm{M}$ sucrose (suc) and then with $0.1 \mathrm{~m}$ sucrose plus BL (suc $+\mathrm{BL}$ ) to activate bitter-sensitive cells. Data from Gr66a > ChR2 flies are displayed in blue, and those from control strains (Gr66a-Gal4 and UAS-ChR2; noted as Gr66a and (hR2, respectively) are in white. We observed a reduction of PERs in Gr66a > ChR2 flies in response to suc + BL ( $p=0.02$, Fisher's exact test) but not in the control strains $(p=1.00)$. We also observed a significant increase in the PR in Gr66a $>$ ChR2 flies in response to suc $+B L(p=0.01)$ but no increase in the control strains $(p=0.745)$. $\boldsymbol{B}$, Flies expressing ChR2 in sugar-sensitive cells (Gr64f $>$ ChR2) were stimulated with BL alone to activate the sugar-sensitive cells $(\mathrm{BL})$ and then with $\mathrm{BL}$ plus $10 \mathrm{~mm}$ strychnine to activate sugarand bitter-sensitive cells (BL + stry). We observed a reduction of the PER in Gr64f $>$ ChR2 flies in response to $\mathrm{BL}(p=0.007)$ but not in the control strains $(p=0.695)$ that were not reacting to BL. We also observed a strong increase of the PR in response to BL in Gr64f $>$ ChR2 flies ( $p=$ 0.0036). Graph legends, statistical tests, and abbreviations are the same as in Figure 1.

tion was the same as before, but the recording (and chemical stimulation) was limited to $2 \mathrm{~s}$. The stimuli used were strychnine (1,5, and $10 \mathrm{~mm})$ "mixed" with BL or $0.1 \mathrm{~m}$ sucrose.

Statistical analysis. The proboscis responses (PERs and PRs) were compared with a Fisher's exact test (two tailed) using R 3.0.2 (R Foundation for Statistical Computing) or Statistica 10 (StatSoft). A 95\% binomial confidence interval was calculated using JavaStat (http://statpages.org/confint.html).

We analyzed the statistical significance of MultiCAFE consumption as in the study by Sellier et al. (2011), using generalized linear mixed models (GLMMs), which provide a flexible approach to correct potential problems of correlation and heteroscedasticity. To model consumption in the MultiCAFE experiment, we used a Gaussian distribution under SAS 9.2 (SAS Institute).

Two-choice feeding tests were analyzed with unpaired Student's $t$ tests with unequal variances to check for significant differences between pairs of data using Statistica 10.

For electrophysiology, we analyzed the data differently according to the questions asked. To compare the firing rate of sensilla stimulated by sugar and sugar plus bitter (see Fig. $5 F-H$ ), we used Wilcoxon's matched pairs tests. For other binary comparisons (see Figs. $5 I-K, 7 B, C, 8 C, E$ ), we used Kruskall-Wallis tests. Last, we used a one-way ANOVA with Fisher's least significant difference (LSD) post hoc analysis to evaluate the effect of strychnine on optogenetic responses (see Fig. $9 A, B$ ). These tests were performed using Statistica 10.

To analyze dose-response curves of our electrophysiological experiments (see Figs. 6, $7 D, E$ ), we fitted GLMMs using SAS 9.2 with a Poisson distribution with overdispersion to model the discrete nature of the number of spikes per second. For sucrose, strychnine, and the mixture of sucrose and strychnine, the models also consider a variance-covariance matrix with an autoregressive structure to account for correlations, because each insect was stimulated with the different concentrations. We partitioned interactions constructing slice $F$ tests and evaluated pairwise differences within single effects with $t$ tests. All these outputs were generated using the GLIMMIX procedure of SAS 9.2.

\section{Results \\ PERs/PRs to stimulation of the labellum with mixtures of sugar/bitter molecules}

Because L-canavanine and strychnine are considered as bitter for Drosophila, we expected that both substances would reduce PERs. When stimulated with sucrose, flies responded to sucrose with a strong PER (Fig. 1B). In response to $10 \mathrm{~mm}$ strychnine mixed with 0.1 m sucrose, Gr66a $>D T I$ flies and their parents showed a strongly reduced PER compared with $0.1 \mathrm{~m}$ sucrose alone $(p<$ 0.001 , Fisher's exact test), whereas L-canavanine had no effect. Only $10-15 \%$ of control flies exhibited a PR in response to 0.1 sucrose (Fig. 1B). Approximately $60-70 \%$ of the flies from control strains retracted their proboscis in response to sucrose plus strychnine or L-canavanine $(p<0.001)$. However, Gr66a $>D T I$ flies responded to the mixture at a level similar to sucrose alone $(p=1)$.

Altogether, these data indicate that strychnine differs from L-canavanine when mixed with sugar, with strychnine inhibiting PER but not L-canavanine, whereas both substances induce the PR. Although PERs seem to be insensitive to the presence or absence of Gr66a cells, the PR is affected strongly by the ablation.

\section{PERs/PRs to stimulation of the legs with mixed or dissociated solutions of sugar/bitter molecules}

We then examined whether similar findings could be obtained by stimulating leg taste receptors. Stimulating these appendages provides us with an additional possibility, which is to present sugar and bitter separately (Fig. $2 A$ ). This was tested on $w^{1118}$ flies, on which we compared PERs/PRs to sugar and strychnine or L-canavanine by stimulating either one leg with the mixture (mixed presentation) or one leg with a bitter substance and the contralateral one with sugar (dissociated presentation; Fig. $2 B$ ). In these conditions, we obtained a highly significant difference of PER between strychnine plus sucrose versus strychnine plus L-canavanine in the mixed presentation $(p<0.000$, Fisher's exact test, two tailed) but not in the dissociated presentation ( $p=$ 0.07 ). This suggests that the mixture of sugar and strychnine is more effective in preventing the initiation of a PER than when the stimuli (at the same concentration) are presented on different legs, even if we can expect to stimulate the same number of taste receptor neurons in both situations.

We then performed the same experiment in Gr66a $>D T I$ flies and their parents (Fig. 2C,D). As expected, the strychnineinduced inhibition of the PER was more marked in the mixed mode than in the dissociated presentation mode in the control strains (Fig. $2 C, D ; p<0.001)$ and Gr66a $>$ DTI flies $(p=0.006)$. With L-canavanine, the situation was different as the PERs were similar in the two modes of presentation (Fig. $2 C, D ; p=1$ ). Although no difference was found in the PRs to sucrose plus strychnine and sucrose plus L-canavanine in both mode of presentations, we found a difference in the PR between Gr66a $>D T I$ flies and their parents for sucrose plus L-canavanine ( $G r 66 a-$ Gal4, $p=0.007$; UAS-DTI, $p=0.003$ ) in the mixed mode and only between one control strain and Gr66a>DTI for the dissociated presentation.

Because Gr66a is not expressed ubiquitously in taste neurons detecting bitter chemicals on the tarsi (Ling et al., 2014), we also tested ablating cells expressing Gr33a, which is expressed in bitter-sensitive cells (Moon et al., 2009; Lee et al., 2010). A 
A
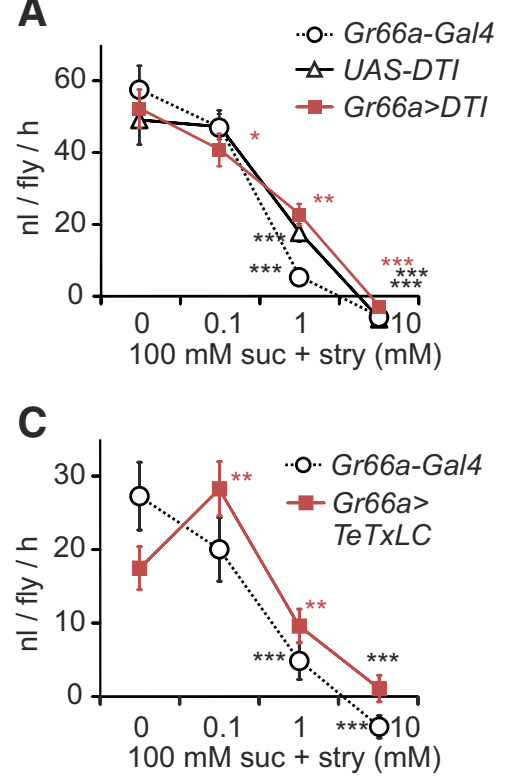

E

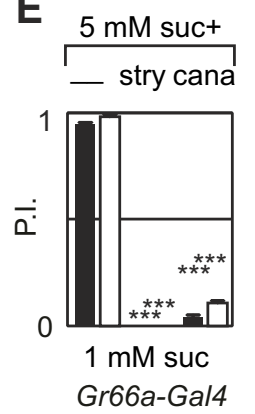

B

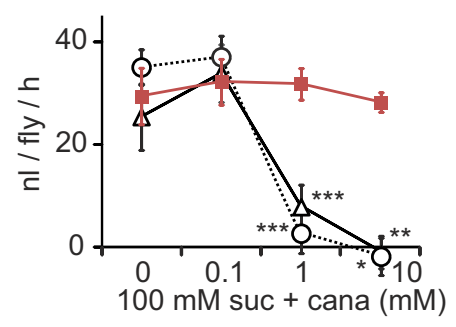

D
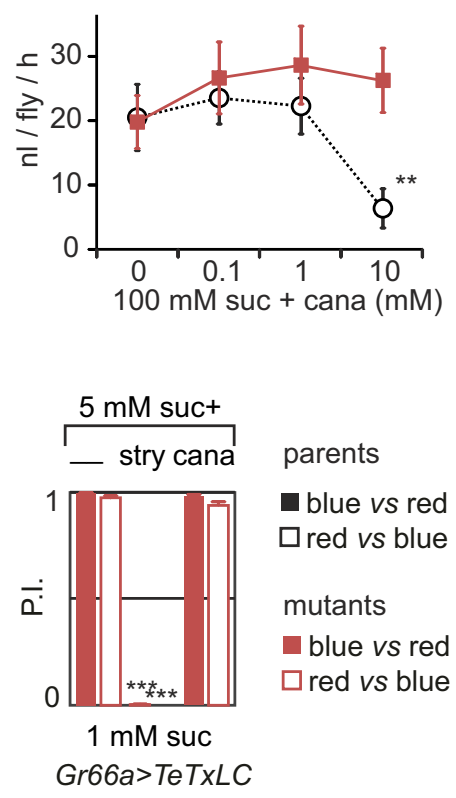

Figure 4. Flies with ablated bitter-sensitive cells are still able to avoid sucrose solutions containing strychnine in MultiCAFE and binary choice tests. $\boldsymbol{A}-\boldsymbol{D}$, Flies were given access to $5 \mu \mathrm{l}$ capillary tubes filled with $100 \mathrm{~mm}$ sucrose and different concentrations of strychnine or L-canavanine. We measured the consumption of groups of 20 flies during $2 \mathrm{~h}$ in the dark (nanoliters per fly per hour), displaying the results as mean \pm SEM. The differences between consecutive concentrations were determined using GLMM $\left({ }^{*} p<\right.$ $0.05,{ }^{* *} p<0.01,{ }^{* * *} p<0.001$; nonsignificant values are not reported on the graph). $\boldsymbol{A}$, We observed a significant reduction of consumption according to strychnine concentration $(0,0.1,10$, and $10 \mathrm{~mm}$ ) mixed with $100 \mathrm{~mm}$ sucrose in Gr66a $>$ DTI flies (with bitter-sensitive cells ablated) and in their parental lines (Gr66a-Gal4 and UAS-DTI) ( $n=13$ repetitions for each strain). B, We also observed a significant reduction of consumption according to L-canavanine $(0,0.1,1$, and $10 \mathrm{~mm})$ mixed with $100 \mathrm{~mm}$ sucrose in the parental lines (UAS-DTI, $n=8$; Gr66a-Gal4, $n=12$ ) but not in Gr66a >DTI flies ( $n=13$ ). $\boldsymbol{C}-\boldsymbol{E}$, To confirm that the DTI could be replaced by another method of impairing cells expressing Gr66a, we used TeTxLC to selectively inactivate the synapses of these cells. $\boldsymbol{C}$, We observed a significant reduction of consumption in response to strychnine mixed with sucrose in one parental line (Gr66a-Gal4, $n=10)$ and $G r 66 a>D T I$ flies $(n=7)$. D. We observed also a reduction of consumption in response to L-canavanine mixed with sucrose in the parental line tested (Gr66a-Gal4, $n=10)$ but not in Gr66a>DTI flies $(n=10)$. $\boldsymbol{E}$, Flies expressing the TeTxLC were also tested in a two-choice test, in which groups of 80 flies were given access to agar wells filled with a red or blue food dye mixed with either $1 \mathrm{~mm}$ sucrose or $5 \mathrm{~mm}$ sucrose plus $30 \mathrm{~mm}$ L-canavanine or $10 \mathrm{~mm}$ strychnine. After feeding $2 \mathrm{~h}$ in the dark, we measured the proportion of flies with their abdomen colored in blue, red, or pink to compute a PI $\left[\mathrm{PI}=\left(n \_\right.\right.$blue $+n \_$pink/2) $/\left(n \_b l u e+n \_\right.$pink + $n \_$red)] and performed the same experiment after inverting the dyes (black bars, blue vs red; white bars, red vs blue; $n=4$ repetitions for each condition). The statistical significance of the results was evaluated with unpaired Student's $t$ tests with unequal variances. We observed a strong reduction of $\mathrm{PI}$ when sugar was mixed with strychnine or L-canavanine in the parental lines ( $p<$ 0.0001). In Gr66a $>$ TeTXLC flies, we observed also a strong reduction of the consumption in the presence of strychnine $(p<0.001)$ but not with L-canavanine $(p=0.19-0.13)$. The data are represented as the mean \pm SEM using the same conventions as in other figures for indicating the statistical significance level. suc, Sucrose; cana, L-canavanine; nico, nicotine; caff, caffeine; lob, lobeline; stry, strychnine; den, denatonium.

difference in the PRs to sucrose plus L-canavanine between the control strains and Gr33a>DTI flies was observed (Fig. $2 E, F$ ) as in $G r 66 a>D T I$ flies. In addition, significant differences were observed in the PERs to sucrose plus strychnine in both presentation modes.

These observations suggest that taste cells expressing Gr66a and Gr33a play a role in triggering PRs (as found on the pro-

boscis) and also that Gr33a cells contribute to prevent PERs. However, in all strains tested here, the effect of strychnine was more potent on the PER when presented within a mixture than when presented separately, whereas the mode of presentation had no effect on the PR.

PERs/PRs to sugar and optogenetic activation of bitter-sensitive cells

To test whether activating bitter cells per se is sufficient to reduce sugar-induced PERs, we expressed ChR2 into Gr66a cells to activate them with light (Fig. $3 A$ ). In Gr66a $>$ ChR2 flies, we observed a 22\% reduction of the PER by BL (Fisher's exact test, $p=0.024$; Fig. $3 A$ ), although no effect was observed in the control strains (Gr66a-Gal4 and UAS-ChR2; $p=1.000$ ). We observed a significant increase of the PR in Gr66a $>C h R 2$ flies stimulated with sucrose plus BL compared with sucrose alone $(p=0.011$; Fig. $3 A)$, although no effect was detected in control flies $(p=$ $0.7445)$.

Thus, the optogenetic activation of Gr66a cells of the legs and the proboscis exerts only a moderate inhibition of the PER but a marked effect on the PR, mimicking the effect of the dissociated presentation mode with strychnine (Fig. 2C,D) and of $\mathrm{L}$-canavanine on responses on the labellum (Fig. 1B,C).

\section{PERs/PRs to optogenetic activation of sugar-sensitive cells and strychnine} Conversely, we expressed ChR2 into Gr64f cells to mimic the effect of sugar with light (Fig. 3B). Gr64f $>C h R 2$ flies responded to BL stimulation with a robust PER, whereas flies from the control strains did not respond (Fig. 3B). We found an $\sim 29 \%$ reduction in the PER when Gr64f $>C h R 2$ flies were stimulated with BL plus $10 \mathrm{~mm}$ strychnine compared with BL plus water (as control for the tactile stimulation; Fisher's exact test, $p=$ $0.0073)$. No difference was observed in the PER when the control strains were stimulated with $\mathrm{BL}$ plus water and $\mathrm{BL}$ plus strychnine $(p=0.695)$. A significant increase in the PR was observed when Gr64f $>$ ChR2 flies were stimulated with BL plus strychnine compared with BL plus water alone $(p=0.0036)$.

In summary, the BL-induced PER is inhibited by strychnine to an extent comparable with the dissociated presentation (Fig. 2B).

\section{Behavioral responses of flies to sugar/bitter solutions in MultiCAFE and two-choice tests}

Our observations on PERs/PRs indicate that strychnine mixed with sucrose plays a stronger role than strychnine alone, whereas 
A

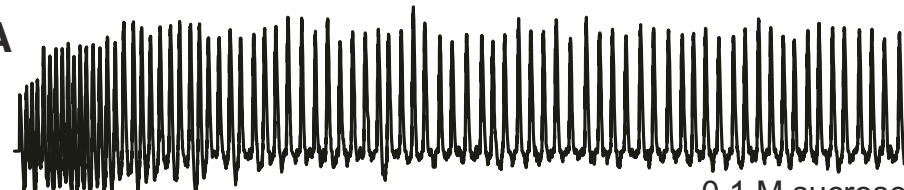

$0.1 \mathrm{M}$ sucrose
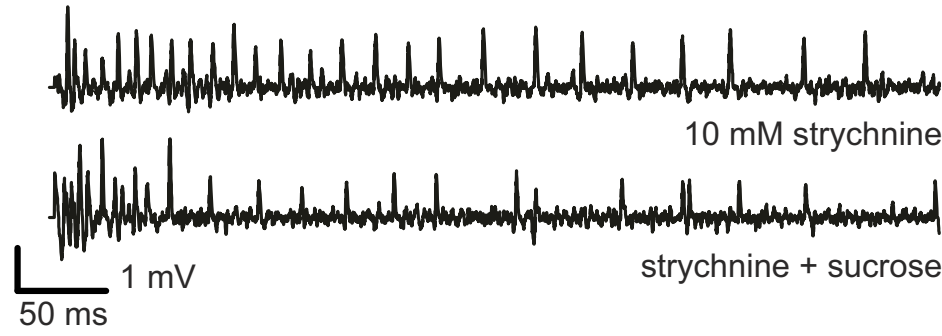

C

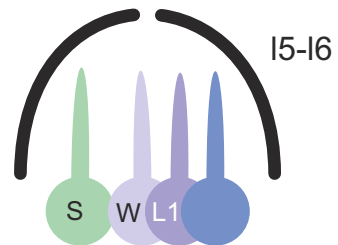

F
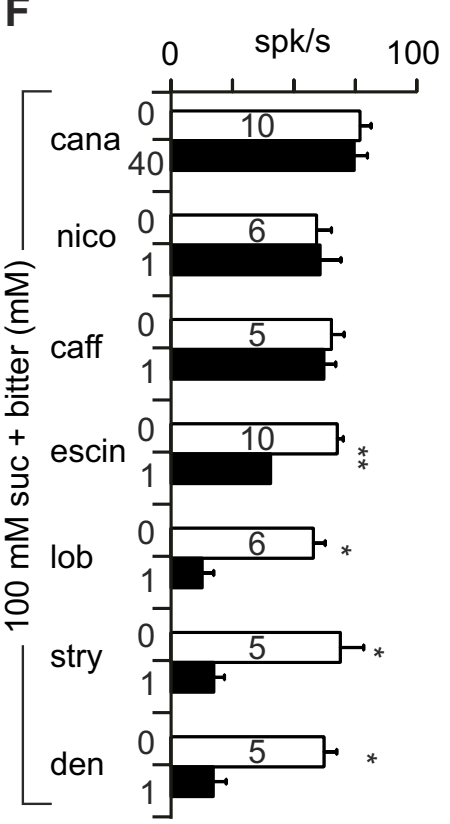

I

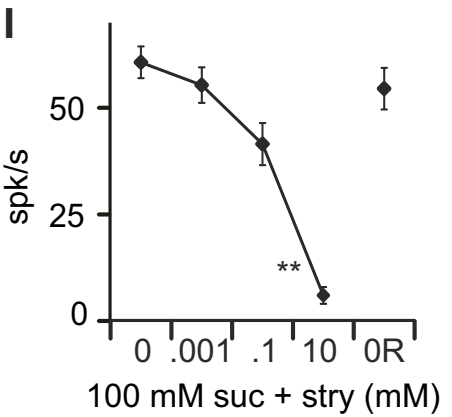

D

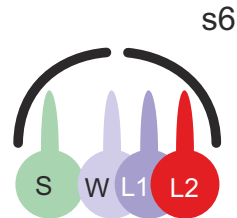

G

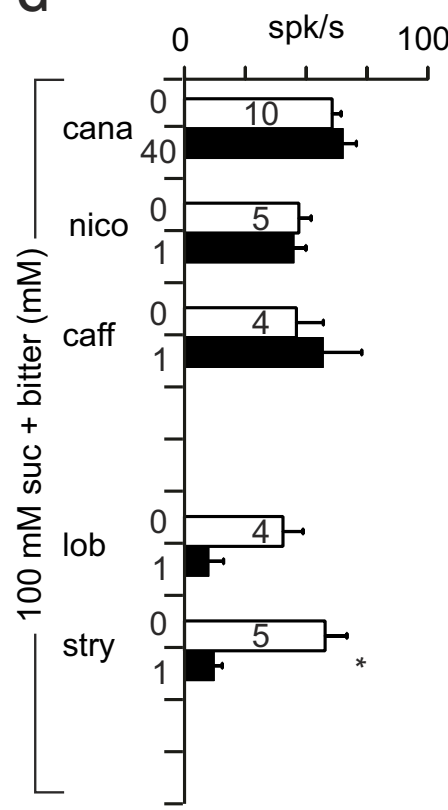

J

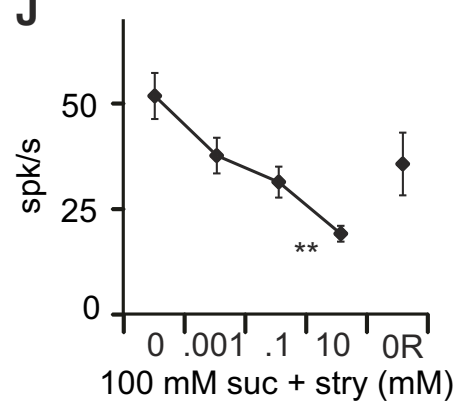

B s6

15

i9

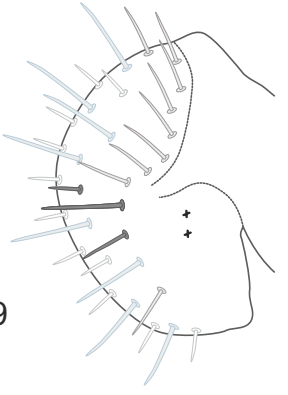

E

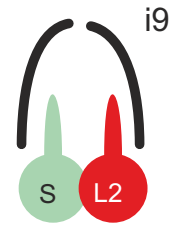

H
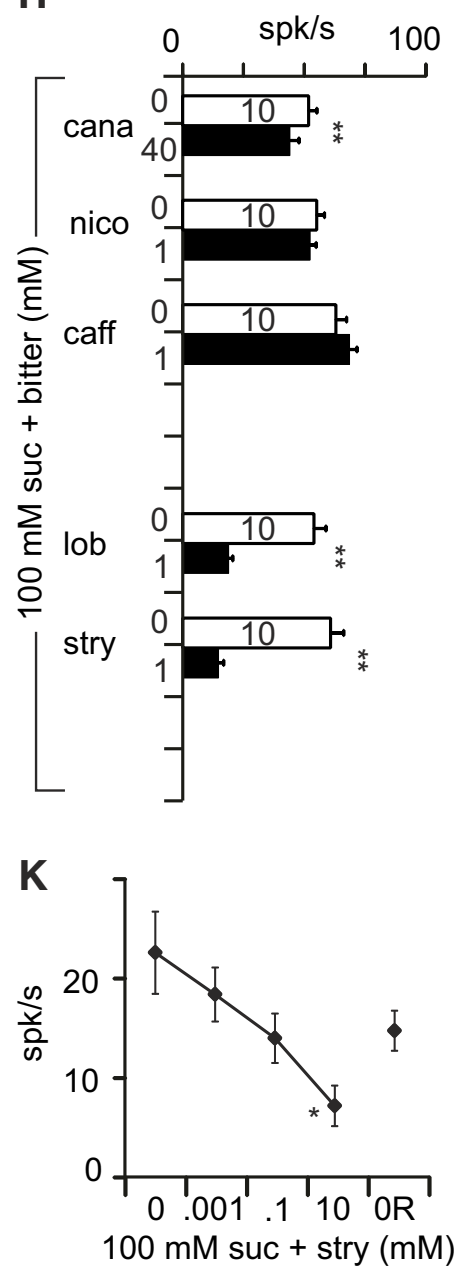

Figure 5. Bitter chemicals differ in their capacity to inhibit sucrose detection. $A$, Representative sample of strychnine-induced inhibition of the responses to sugar in taste sensilla obtained with a tip-recording electrode. Top trace shows the first $500 \mathrm{~ms}$ of a recording in which one neuron is firing vigorously when stimulated with $0.1 \mathrm{~m} \mathrm{sucrose}$ ( $+100 \mathrm{~mm}$ TCC used as an electrolyte). The middle trace shows the activation of another neuron in response to $10 \mathrm{~mm}$ strychnine. The bottom trace shows the firing activity recorded in response to a mixture of these two stimuli with much less action potentials than expected if the two neurons would react to sugar and strychnine independently. $\boldsymbol{B}$, Location of the taste sensilla mostly recorded from in this study, using a map notation introduced by Hiroi et al. (2002) and cellular composition of the sensilla tested 15 and 16 sensilla host four taste cells $(\boldsymbol{C})$ and $s 6$ sensilla (D), whereas i9 sensilla host only two taste cells (E). These taste cells are labeled according to their sensitivity as S (sugar-sensitive), W (water-sensitive), L1 (low salt-sensitive), and L2 (bitter-sensitive). Bitter chemicals (but not all) (Figure legend continues.) 
whether L-canavanine is mixed or alone makes no difference. Because these observations were performed on a short timescale (within seconds), these differences may not affect feeding activities on a longer timescale, which are regulated by post-ingestive mechanisms. Insects are indeed capable of rejecting noxious substances through post-ingestive mechanisms (Glendinning, 1996; Wright et al., 2010) and to quickly learn the nutritive value of food (Burke and Waddell, 2011; Dus et al., 2011; Fujita and Tanimura, 2011; Gruber et al., 2013; Bjordal et al., 2014). Thus, we evaluated whether defects in peripheral detection of bitter molecules inherent in Gr66a $>$ DTI flies would be compensated for in behavioral tests lasting several hours.

In MultiCAFE assays, Gr66a $>D T I$ flies and their parental lines preferred feeding from capillary feeders without strychnine in relation to the dose ( $p<0.001$, GLMM; Fig. $4 A$ ). However, Gr66a $>D T I$ flies did not discriminate between sugar solutions containing different concentrations of L-canavanine ( $p=0.967$; Fig. $4 B$ ), whereas the parental lines had no difficulty avoiding 1 and $10 \mathrm{~mm}$ L-canavanine mixed with sugar $(p<0.001$, GLMM; Fig. 4B),

To confirm that these differences were not attributable to the diphtheria toxin, we silenced bitter-sensitive cells using TeTxLC. In a MultiCAFE assay, Gr66a > TeTxLC flies and one parental line preferred feeding from capillaries without strychnine in relation to the dose ( $p<0.001$, GLMM; Fig. 4C). However, Gr66a $>$ TeTxLC flies did not discriminate between different solutions of L-canavanine $(p=0.2088$; Fig. $4 D)$, whereas one parental line avoided sucrose solutions containing $10 \mathrm{~mm}$ L-canavanine $(p<0.0001$, GLMM; Fig. 4D).

We further tested these flies in a two-choice feeding assay. In the presence of strychnine, both parental lines and Gr66a $>$ TeTxLC flies completely avoided the treated wells ( $p<0.001$, unpaired Student's $t$ test; Fig. $4 E$ ). In contrast, Gr66a $>T e T x L C$ flies were unable to detect L-canavanine (blue/red, $p=0.191$; red/blue, 0.131 ). One parental line (Gr66a-Gal4) completely avoided L-canavanine $(p<0.001)$, whereas the other (UAS-TeTxLC) was less sensitive. This is likely attributable to a genetic background effect (blue/red, $p=0.0001$; red/blue, $p<0.001$ ).

Altogether, these results indicate that bitter cells expressing Gr66a are necessary to detect L-canavanine but are dispensable for detecting strychnine in both MultiCAFE and two-choice feeding assays, which assess feeding behavior over a $2 \mathrm{~h}$ timeframe.

\section{$\leftarrow$}

(Figure legend continued.) elicit spiking responses in i9 and $s 6$ sensilla but not in 15 and 16 sensilla. $\boldsymbol{F}-\boldsymbol{H}$, Extracellular spiking activity recorded with sucrose mixed with different bitter chemicals recorded in $w^{1718}$ flies in $15(\boldsymbol{F}), s 6(\boldsymbol{G})$, and i9 $(\boldsymbol{H})$ sensilla. We compared the responses to $100 \mathrm{~mm}$ sucrose (suc; white bar) with the responses to $100 \mathrm{~mm}$ sucrose mixed with a bitter chemical (black bar). The molecules tested were L-canavanine (cana), nicotine (nico), caffeine (caff), escin, lobeline (lob), strychnine (stry), and denatonium (den). All molecules were at $1 \mathrm{~mm}$, except $40 \mathrm{~mm}$ for $\mathrm{L}-$ canavanine. Data are displayed as the mean and SEM ( $n=4-10$ as reported on the bar of each graph). The difference between the response to sucrose (first presentation) and to the mixture was determined using Wilcoxon's matched pairs tests. $\boldsymbol{I}-\boldsymbol{K}$, Extracellular spiking activity in response to $100 \mathrm{~mm}$ sucrose mixed with different concentrations of strychnine in $16(I)$, s6 $(J)$, and i9 $(K)$ sensilla. We measured the spiking activity (spikes not sorted) in response to $100 \mathrm{~mm}$ sucrose mixed with increasing concentrations of strychnine $(0,0.001,0.1$, and $10 \mathrm{~mm}$ ). Sucrose alone was tested at the end of the experiment again to evaluate the response recovery (OR). $n=5-6$ for each stimulation. Error bars represent SEM. The statistical significance was estimated with a Kruskall-Wallis test, with strychnine concentration as a categorical predictor. ${ }^{*} p<0.05,{ }^{* *} p<0.01,{ }^{* * *} p<0.001$.

\section{Electrophysiological responses of labellar taste sensilla to sucrose mixed with different bitter molecules}

To examine the cellular basis of these behavioral observations, we looked at the electrophysiological responses of taste sensilla stimulated with sucrose, with a bitter molecule, and with their mixture. As noted in previous studies (Meunier et al., 2003a; Jeong et al., 2013), whereas sucrose activates a cell and strychnine activates another cell, when the two chemicals are mixed, the resulting response is much less than expected by simply summing the activity of the two cells to each chemical (Fig. 5A).

We examined taste sensilla of the proboscis (Fig. $5 B$ ) that are mapped and identified according to their length and position (Shanbhag et al., 2001; Hiroi et al., 2002). Short-type sensilla (s-type) and long-type sensilla (l-type) house four taste neurons, whereas intermediate-sized (i-type) sensilla house only two taste neurons. In s-type sensilla, each taste neuron responds to different groups of molecules: sugars (Hiroi et al., 2002, 2004), water (Cameron et al., 2010; Chen et al., 2010), salts (Meunier et al., 2003b) or pheromones (Thistle et al., 2012), and bitter chemicals (Hiroi et al., 2002; Dahanukar et al., 2007; Weiss et al., 2011; Fig. 5C-E, cells S, W, L1, and L2, respectively). In 1-type sensilla, three of these cells are present, but none is responding to bitter chemicals (Hiroi et al., 2002; Weiss et al., 2011). In i-type sensilla, one neuron responds to sugars whereas the other responds to bitter molecules (Hiroi et al., 2004; Fig. 5E, cells $\mathrm{S}$ and $\mathrm{L} 2$, respectively).

First, we examined whether all bitter chemicals would inhibit sugar-sensitive cells by recording the responses of taste sensilla 15-16, s6, and i9 to sucrose, and then to sucrose mixed with a bitter molecule (Fig. $5 F-H$ ). An additional stimulation with sucrose was made to ensure that cells were not intoxicated. Sensilla for which the response to the third stimulation with sucrose was suppressed were discarded. This was to ensure that any observed reduction in response to sucrose when mixed with bitter molecules was attributable to a sensory inhibition rather than an enduring toxic effect. Unless otherwise noted in this series of measurements and in all other experiments, we report on the total number of spikes detected during the first second of each recording. The spikes were not sorted and thus could represent the activity of several neurons.

In 15-16 sensilla, we observed a reduction of activity when 100 mM sucrose was mixed with $1 \mathrm{~mm}$ lobeline, strychnine, denatonium, or escin (Wilcoxon's paired test, $p=0.005,0.028,0.043$, and $0.043 ; n=10,6,5$, and 5 respectively; Fig. $5 F$ ). We did not observe a statistically significant reduction of activity with $1 \mathrm{mM}$ caffeine, $1 \mathrm{~mm}$ nicotine, or $40 \mathrm{~mm}$ L-canavanine ( $n=10,6$, and 5 , respectively; Fig. $5 F$ ). Similar results were obtained with s6 sensilla $(n=4-10)$, in which only strychnine was found to inhibit sugar detection to a statistically significant level ( $p=0.04, n=5$; Fig. $5 G)$. In i9 sensilla $(n=10)$, L-canavanine, strychnine, and lobeline were found to inhibit sugar detection ( $p=0.008,0.005$, and 0.005 , respectively; Fig. $5 H$ ).

We further examined the effect of increasing concentrations of strychnine on the response to $100 \mathrm{~mm}$ sucrose in these sensilla (Fig. 5I-K). We observed a consistent reduction in response to sucrose when mixed with $10 \mathrm{~mm}$ strychnine in 16 (KruskallWallis test, $p=0.001)$, i9 $(p=0.04)$, and s6 sensilla ( $p=0.003)$. In all three sensilla, the response to sucrose at the end of the experiment was not statistically different from the response to sucrose at the beginning of the series $(p=1.000)$. 


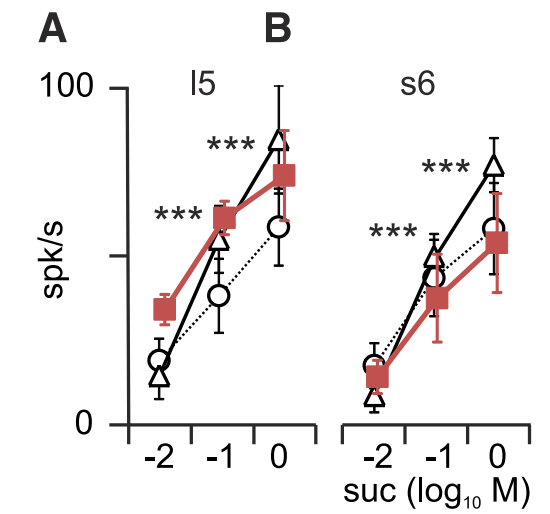

C
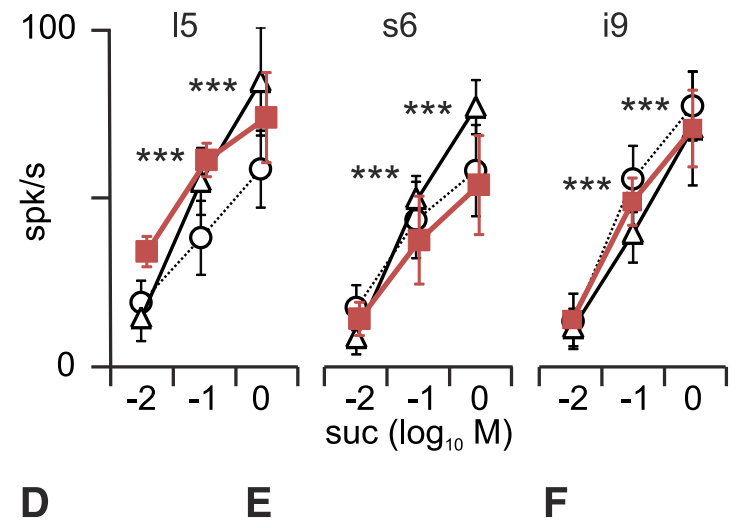

E
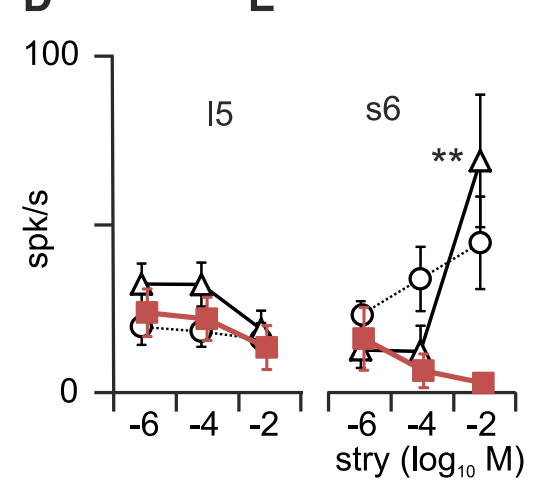

$\mathbf{F}$
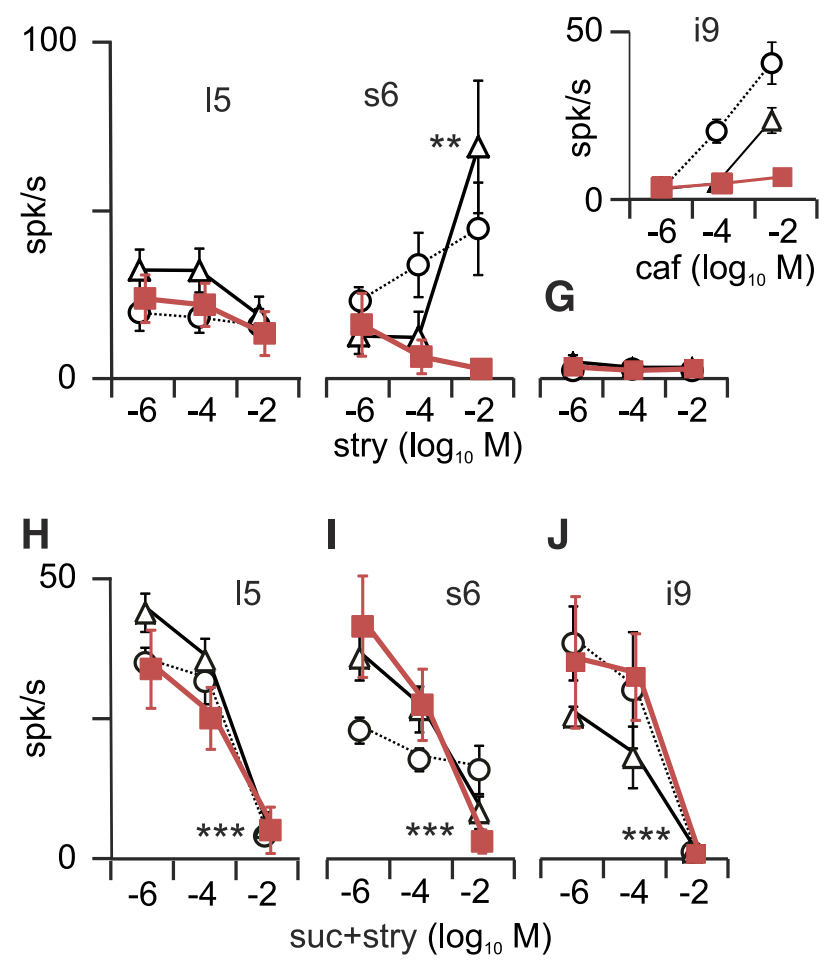

$-\neg$ UAS-DTI $\quad \cdots$ O Gr66a-Gal4

\section{Gr66a>DTI}

Figure 6. Strychnine inhibition of sucrose responses persists in labellar $s 6, i 9$, and 15 sensilla of $\mathrm{Gr} 66 \mathrm{a}>\mathrm{DT} / \mathrm{flies}$. Extracellular responses recorded from sensilla on the labellum (mean \pm SEM) in 56 (left), 15 (middle), and i9 (right) sensilla in Gr66a $>$ DTI (red squares) and the parental lines (triangle, UAS-DTI; circle, Gr66a-Gal4). A-C, Responses to 0.01, 0.1 and $1 \mathrm{~m}$ sucrose were dose dependent in all strains in s6 sensilla $(\boldsymbol{A} ; \mathrm{Gr} 66 \mathrm{a}>\mathrm{DTI}, n=$ $6 ;$ Gr66a-Gal4, $n=5 ;$ UAS-DTI, $n=5)$, I5 sensilla ( $\boldsymbol{B} ; n=7,6$, and 5 , respectively), and i9 sensilla (C; $n=11,6$, and 5, respectively). $\boldsymbol{D}-\mathbf{G}$, Responses to $0.001,0.1$, and $10 \mathrm{~mm}$ strychnine were reduced in $s 6$ sensilla (D) of Gr66a $>$ DTI flies $(n=7,6$, and 5, respectively) but not in 15 sensilla $(\boldsymbol{E})$ that are not activated in response to bitter chemicals $(n=$ $6,5$, and 6 , respectively) and in i9 sensilla ( $\boldsymbol{G})$ that are not sensitive to strychnine $(n=10$, 5 , and 5 , respectively). $\boldsymbol{F}$, To check that the bitter-sensitive neuron was ablated in i9 sensilla, we tested the responses to $0.001,0.1$, and $10 \mathrm{~mm}$ caffeine $(n=11,5$, and 5 , respectively). $\boldsymbol{H}-\boldsymbol{J}$, Responses to a mixture of $0.1 \mathrm{~m}$ sucrose and $0.001,0.1$, and $10 \mathrm{~mm}$ strychnine in s6 sensilla $(\boldsymbol{H} ; \boldsymbol{n}=6,6$, and 5 , respectively), 15 sensilla $(\boldsymbol{I} ; \boldsymbol{\eta}=7,6$, and 5 , respectively) and i9 sensilla $(J ; n=11,5$, and 5 , respectively). A dose-dependent effect of strychnine was found in all three sensilla in the three strains. These data were analyzed with a GLIMMX procedure. Abscissa, $\log _{10}$ of the molar concentration. ${ }^{* *} p<0.01$, ${ }^{* * *} p<0.001$. suc, Sucrose; stry, strychnine; caf, caffeine.
A

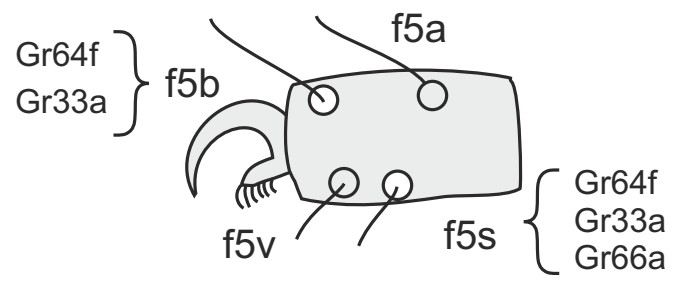

B

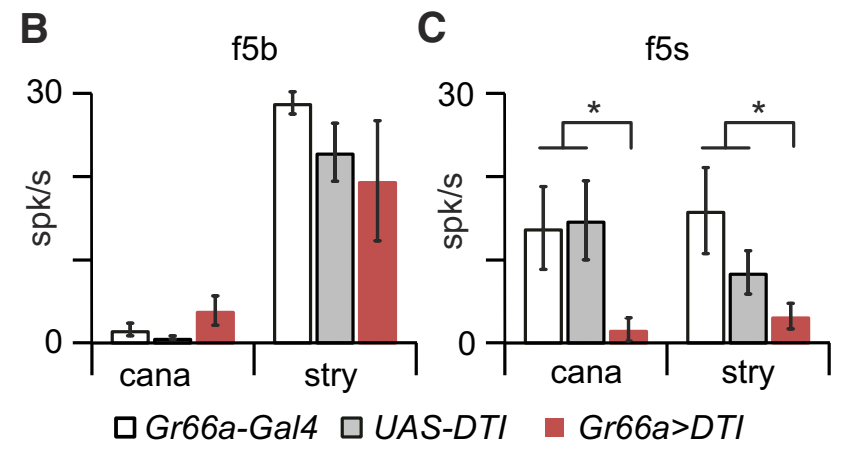

C

f5s

D

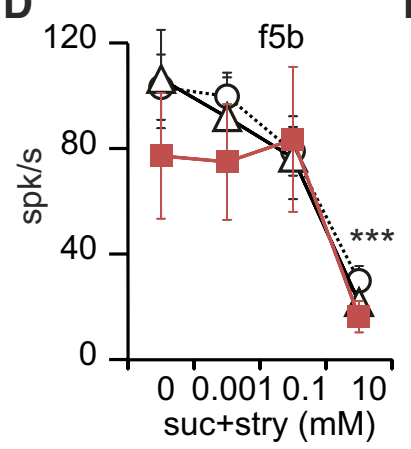

E

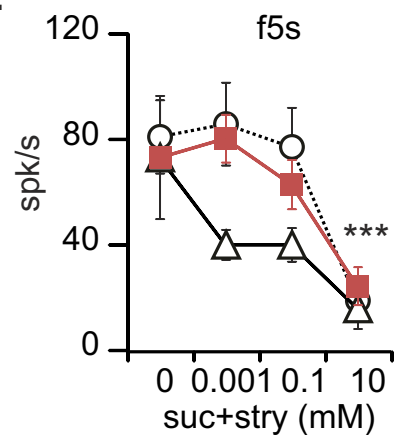

$\triangle$ UAS-DTI $\quad-$ - Gr66a-Gal4

- Gr66a>DTI

Figure 7. Strychnine inhibition of the responses to sucrose persists in tarsal f5b and f5s sensilla of Gr66a > DTI flies. A, Schematic drawing of the position of f5b and f5s sensilla on the fifth tarsus of female flies. According to Ling et al. (2014), only f5s express Gr66a, which means that f5b should remain functional in Gr66a $>$ DTI flies. B, C, Extracellular spiking activities (mean \pm SEM) recorded in responses to strychnine and L-canavanine in Gr66a $>D T I$ (red bars), UAS-DTI (gray bars), and Gr66a-Gal4 (white bars) flies. $\boldsymbol{B}$, In f5b sensilla, the responses of the three strains are equivalent with respect to $10 \mathrm{~mm}$ strychnine (Gr66a $>$ DTIvs UAS-DTI, $p=0.55$ and Gr66a $>$ DTI vs Gr66a-Gal4, $p=0.50, n=4-7$; Kruskall-Wallis test) and $40 \mathrm{~mm}$ L-canavanine (Gr66a $>$ DTI vs UAS-DTI, $p=1.00$ and Gr66a $>$ DTI vs Gr66a-Gal4, $p=0.76, n=4-8$ ). C, In f5s sensilla, we found a significant difference in the responses to $10 \mathrm{~mm}$ strychnine between Gr66a $>D T I$ and the parental lines (Gr66a $>$ DTI vs Gr66a-Gal4 + UAS-DTI, $p=0.011, n=4-6$ ) and $40 \mathrm{mM}$ L-canavanine (Gr66a $>$ DTIvs Gr66a-Gal4 + UAS-DTI, $p=0.015, n=3-7)$. D, E, We furthertested the responses to $0.1 \mathrm{~m}$ sucrose mixed with strychnine $(0,0.001,0.1$, and $10 \mathrm{~mm}$ ) in Gr66a $>D T I$ (red squares), UAS-DTI (white triangle), and Gr66a-Gal4 (white circle) flies. In f5b sensilla (D) and f5s sensilla $(E)$ in the three genotypes $(n=4-10)$ in which we found a significant effect of concentration in f5b sensilla ( $p<0.001$, GLMM procedure) and f5s sensilla ( $p=0.0011, \mathrm{GLMM}){ }^{*} p<0.05$, ${ }^{* * *} p<0.001$. cana, $\mathrm{L}-$ Canavanine; stry, strychnine; suc, sucrose.

\section{Electrophysiological responses of labellar taste sensilla of Gr66a $>$ DTI flies}

Our behavioral observations together with our initial electrophysiological recordings suggest that strychnine inhibits sugar-detection cells and activates bitter-sensitive cells, whereas L-canavanine mostly activates bitter-sensitive cells. To determine whether bittersensitive neurons are required for sugar-sensitive neuron inhibition, we recorded the responses of flies in which cells expressing Gr66a are ablated, using the same genetic construction used in 


\section{A Gr66a $>$ ChR2}

$0.1 \mathrm{M}$ suc

BL
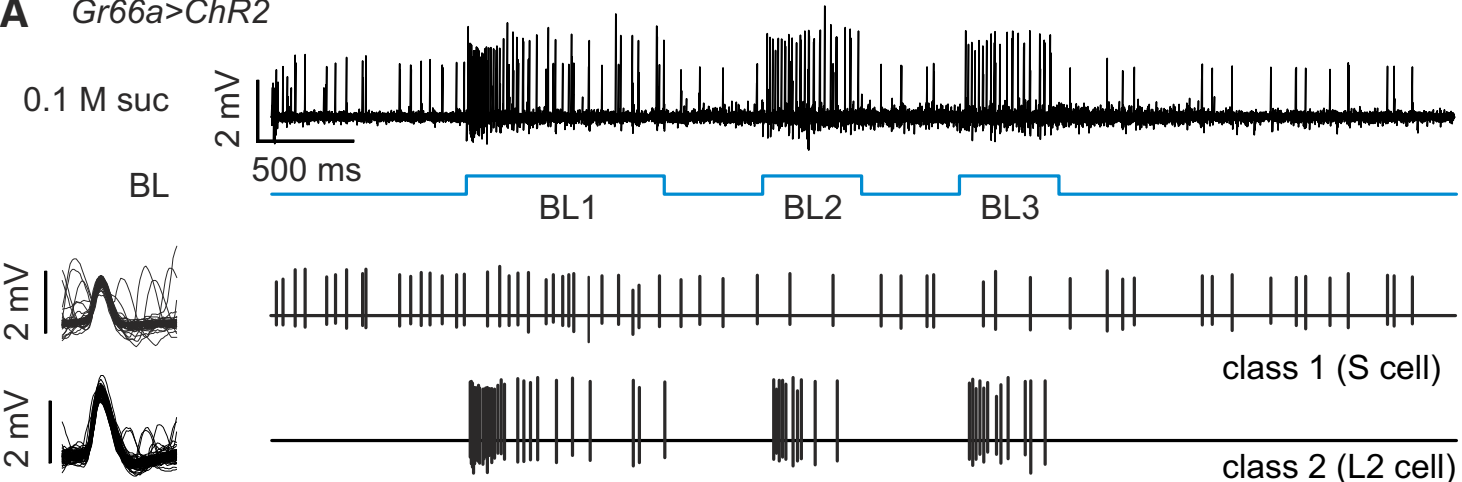

class 1 ( $\mathrm{S}$ cell)

class 2 (L2 cell)

B

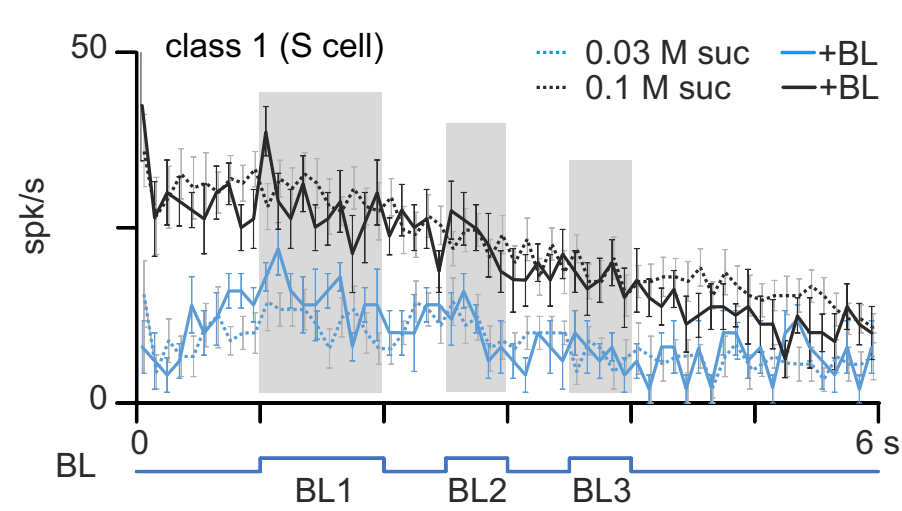

D

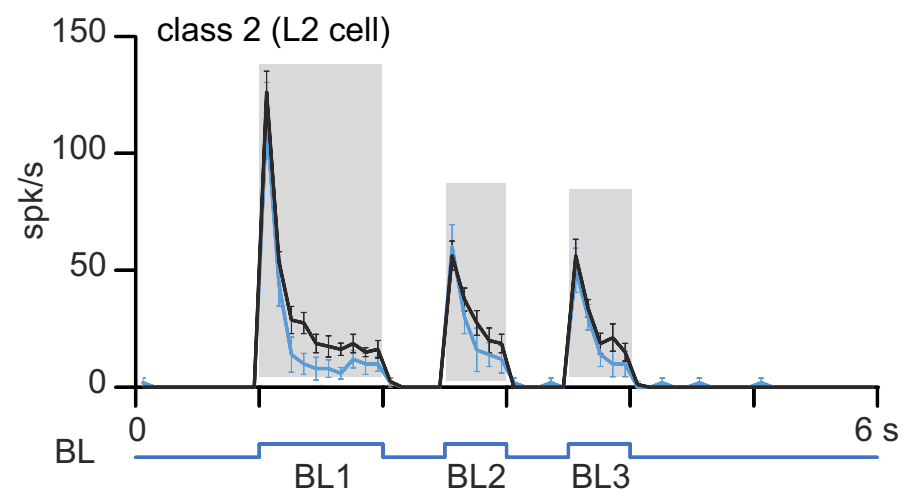

C

$\square \operatorname{suc}(1)$

suc+BL

$\square \operatorname{suc}(2)$

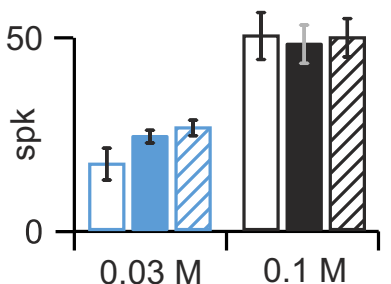

E
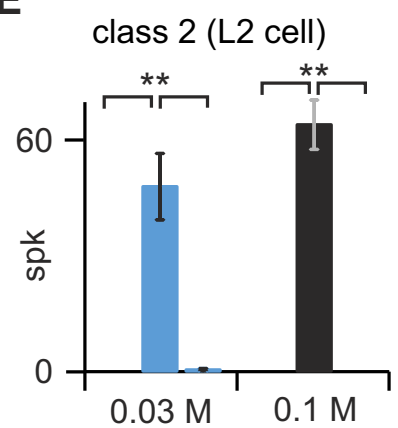

Figure 8. Optogenetic activation of the bitter-sensing cell does not inhibit responses to sugar. $A$, Labellar sensilla of Gr66a $>$ ChR2 flies were stimulated with sucrose (suc) and BL ( 3 bursts of $1 \mathrm{~s}$, BL1; $0.5 \mathrm{~s}, \mathrm{BL} 2$ and BL3). The recordings were performed in i9 sensilla in which two classes of spikes can be separated on the basis of their amplitude, shape, and temporal occurrence. The spikes extracted from the sample recording (top trace) are displayed below as a succession of bars at the same timescale and on the left by superimposing each spike of the series in a $6 \mathrm{~ms}$ window. Small spikes corresponded to the activity of a cell responding to sucrose, called S. Larger-amplitude spikes corresponded to the activity of a neuron responding to BL (and to bitter chemicals), called L2. $\boldsymbol{B}$, Spiking activity of S-cells in response to sucrose at 2 concentrations ( $0.1 \mathrm{M}$, black curves; $0.03 \mathrm{M}$, blue) with or without optogenetic stimulation (continuous and dotted lines, respectively). Each point of the curve represents the number of spikes in $100 \mathrm{~ms}$ bins (mean $\pm \mathrm{SEM} ; n=5-15$ recordings). The number of spikes occurring during the three intervals BL1, BL2, and BL3 were added to compare the activity of the neuron in the presence or absence of BL. C, Histogram of the number of spikes recorded (mean $\pm S E M ; n=3-9$ ) during the presentation of BL (BL1 $+B L 2+B L 3$, shaded area in $\boldsymbol{B}$ ). Each sensilla were stimulated with sucrose only before [suc(1), open bars] and after [suc (2), hatched bars] the optogenetic stimulation (suc + BL, filled bar). Sucrose was presented at 2 concentrations: $0.03 \mathrm{~m}$ (blue bars) and $0.1 \mathrm{~m}$ (black bars). The statistical significance of the differences between the responses in the three situations were evaluated with a Kruskall-Wallis ANOVA. D, Spiking activity of $L 2$ cells extracted from the same recordings displayed in $\boldsymbol{B}$. $\boldsymbol{E}$, Histograms of the responses of $L 2$ cells in the same recordings as in $\boldsymbol{C}$. ${ }^{* *} p<0.01$.

the behavioral experiments $(G r 66 a>D T I)$, in sensilla with four taste neurons (15, s6), and with two neurons (i9; Fig. 5C-E).

With sucrose (Fig. $6 A-C$ ), we observed a dose-dependent response in Gr66a $>D T I$ flies and their parental lines in all sensilla tested ( $p<0.0001$, GLMM). With strychnine (Fig. $6 D, E, G$ ), a dose-dependent response was found in the parental lines in s6 sensilla ( $p<0.001$, GLMM) but not in 15 or i9 sensilla, in which strychnine had been documented to elicit very low responses
(Weiss et al., 2011). In Gr66a > DTI files, the responses to strychnine was suppressed in $s 6$ sensilla ( $p=0.12$, GLMM). To check whether i9 sensilla were responsive to bitter chemicals, we tested them with caffeine (Fig. $6 F$ ).

In response to mixtures of $0.1 \mathrm{M}$ sucrose and strychnine (Fig. $6 \mathrm{H}-\mathrm{J}$ ), we found a reduction of the spiking activity in all sensilla, in the control strains and Gr66a $>$ DTI flies $(p<$ 0.001, GLMM). 
These observations confirm that sugar-induced inhibition is present in sensilla that are missing cells activated by strychnine either naturally as in l-type sensilla or when bitter-sensitive cells (expressing Gr66a) are ablated.

\section{Electrophysiological responses of leg taste sensilla of Gr66/DTI flies}

We also recorded from taste sensilla on the legs, first, to confirm that strychnine inhibits sugar detection and, second, to further establish that some bitter-sensitive neurons are not ablated on the legs in Gr66a>DTI flies. We selected sensilla f5b and f5s (Fig. 7A) because Gr66a is expressed only in f5s, whereas Gr33a is expressed in both (Ling et al., 2014). Therefore, we expected to find in Gr66a>DTI flies a suppression of the responses to strychnine and $\mathrm{L}$-canavanine in $\mathrm{f} 5 \mathrm{~s}$ but not in $\mathrm{f} 5 \mathrm{~b}$.

First, we checked that these sensilla responded to L-canavanine and strychnine and reacted differently to the ablation of Gr66a cells (Fig. $7 B, C$ ). The response to strychnine and to L-canavanine was significantly different in f5s sensilla in Gr66a>DTI flies compared with the parental lines (Gr66a>DTI vs Gr66a-Gal4 + UAS-DTI; strychnine, $p=0.011$; L-canavanine, $p=0.015$, Kruskall-Wallis test; Fig. $7 C$ ) but not in f5b sensilla (strychnine, $p=0.558$ for Gr66a-Gal4 and $p=1.000$ for UAS-DTI; no responses were recorded with L-canavanine; Fig. $7 B$ ).

Then, we looked at the response to mixtures of strychnine with sucrose (Fig. $7 D, E$ ). Strychnine concentration had a highly significant effect in all strains because it inhibited sugar detection in both the parental lines and Gr66a $>$ DTI flies in f5b and f5s sensilla $(p<0.0001$, GLMM).

These data confirm that strychnine inhibits sugar detection in sensilla other than on the labellum and that the construction Gr66a $>$ DTI does not completely abolish the detection of strychnine in all sensilla of the tarsus because f5b sensilla keep their sensitivity toward strychnine (Fig. 7B).

Electrophysiological responses of taste sensilla stimulated with sucrose during optogenetic activation of taste cells expressing Gr66a

Although our previous observations indicate that bitter-sensitive cells are not necessary for inhibiting the detection of sugars, it does not rule out the possibility that activating a bitter-sensing cell could reduce firing in adjacent sugar-sensitive neurons. Such a mechanism has been demonstrated recently in the olfactory system of Drosophila, in which the transient activation of an olfactory receptor neuron (ORN) can inhibit the sustained activity of a neighboring ORN (Su et al., 2012).

We asked whether optogenetic activation of bitter-sensing cells could inhibit the response to sucrose in i9/i8 sensilla of Gr66a $>$ ChR2 flies. In the absence of optogenetic activation, sucrose induced a tonic response in sugar-sensitive cells (Fig. 8B) but not in bitter-sensitive cells (Fig. $8 D$ ). In the presence of light, bitter-sensitive cells displayed a phasic-tonic excitation (Fig. $8 A, D, E)$ that did not affect the time course of the responses to sugar in the sugar-sensitive cells (Fig. $8 B-D$ ).

\section{Electrophysiological responses of sugar-sensitive taste neurons activated optogenetically in the presence of strychnine}

We then asked whether strychnine inhibits sugar-induced responses by interfering with general cellular excitation or whether this inhibition is specific to sugar transduction. To address this question, we used Gr64f $>C h R 2$ flies. If strychnine induces a gen-

\section{A $\quad$ Gr64f $>\mathrm{ChR} 2$}

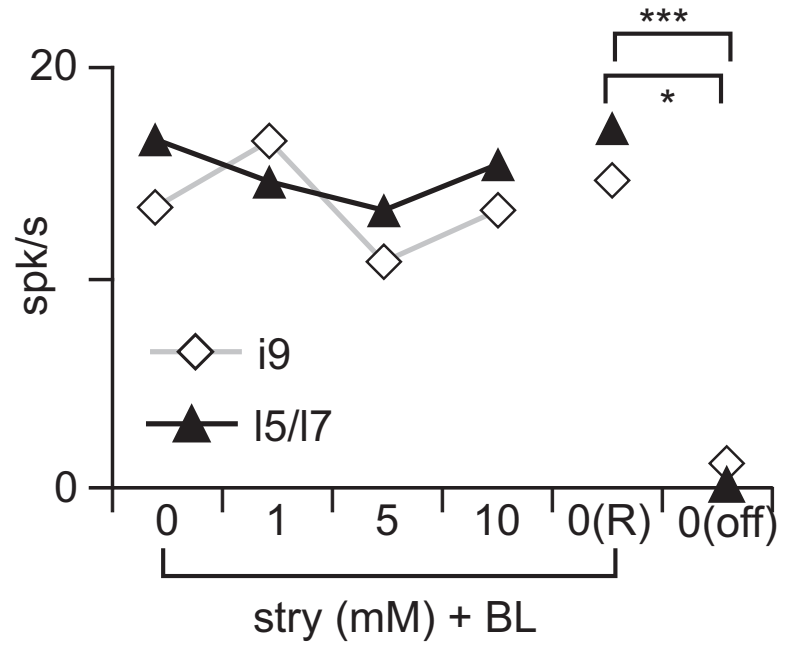

B

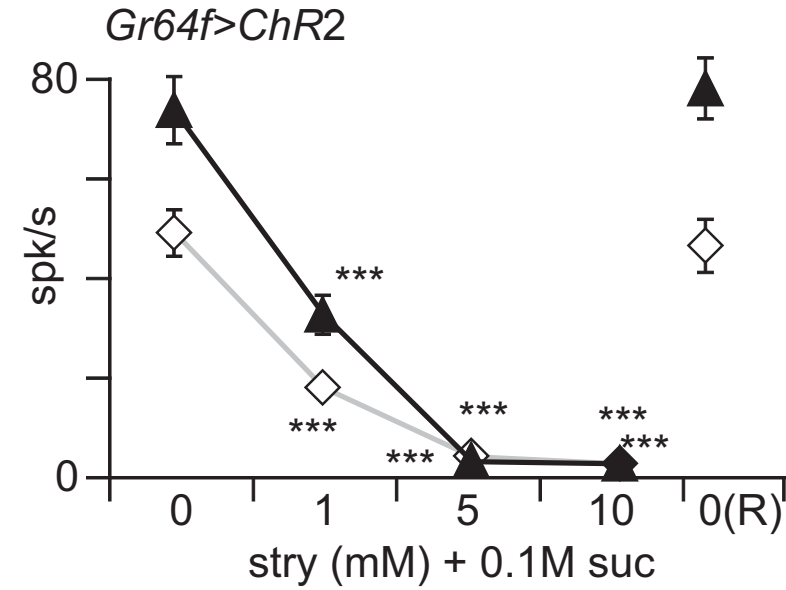

Figure 9. Strychnine does not inhibit responses induced by ectopic ChR2. A, Gr64f $>$ ChR2 flies were stimulated with a $2 \mathrm{~s}$ pulse of $B L$ and concurrently with different concentrations of strychnine. We analyzed the number of spikes (mean \pm SEM) during the first second of the recordings in i9 (white diamonds; $n=7$ ) and $15-17$ (black triangles; $n=11$ ) sensilla in the presence of different concentrations of strychnine delivered sequentially in an increasing order of concentrations $(0,1,5$, and $10 \mathrm{mM})$, followed by BL only $[0(\mathrm{R})]$ and nothing $[0$ (off)]. These data were analyzed with a one-way ANOVA with Fisher's post hoc analysis. No effect of strychnine concentration on the response to $B L$ was observed. Significant differences between 0 (off) and $0,1,5,10$, and $0(R)$ were observed for 19 and $15 / 7$; however, only the interaction between 0 (off) and 0 is shown on graph. $B$, As a control, we verified that Gr64f $>$ ChR2 flies respond to sugar and that these responses are inhibited by strychnine. Black triangles, $15-17$ sensilla $(n=11)$; white diamonds, 9 sensilla $(n=9)$. stry, Strychnine; suc, sucrose; ${ }^{*} p<0.05 ;{ }^{* * *} p<0.001$.

eral inhibition of the sugar-sensing neurons, we would expect it to reduce the response of $G r 64 f>C h R 2$ neurons to BL.

We stimulated i9 and 15-17 sensilla with BL and strychnine (Fig. 9A). No significant effect of strychnine concentration on $\mathrm{BL}$ response was observed (one-way ANOVA, $p=0.79$ for $15-17$ and $p=0.813$ for i9). We found a significant difference between the response of 15-17 and i9 when stimulated with TCC in the presence and absence of BL (Fisher's LSD test, $p<0.001$ for i9 and $p<0.001$ for 15-17). However, in these flies, strychnine inhibited responses to sucrose (Kruskall-Wallis ANOVA by ranks, $p<$ 0.001; Fig. 9B). We infer from this that strychnine does not inhibit sugar-sensing cells but that it directly interferes with sugarspecific reception or transduction pathways. 


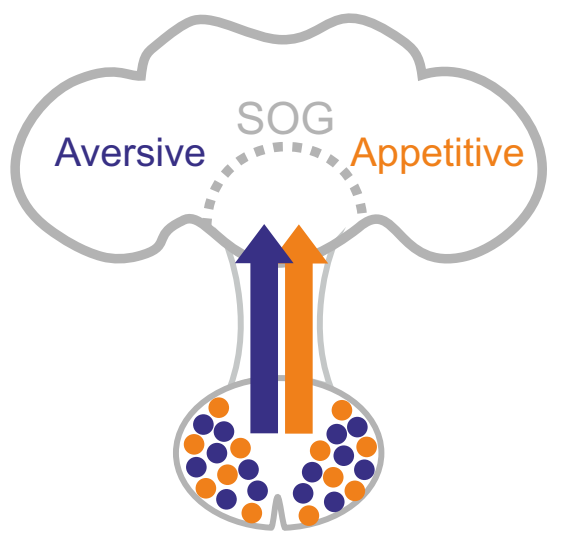

Conflicting messages

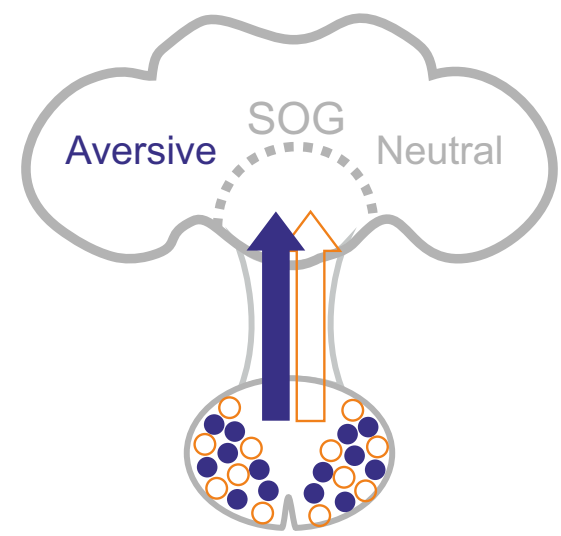

Do not eat this!

Figure 10. Sugar-sensing inhibition simplifies the processing of conflicting messages. Sweet molecules alone are activating $S$ cells (orange dot) that express sugar receptors such as Gr64f. Bitter molecules alone are activating L2 cells (blue dots) that express Gr66a on the labellum. These neurons project in separate areas in the subesophageal ganglion (SOG). In the presence of a mixture of sugar and bitter molecules, if these two detection channels were independent, one would expect the two populations of cells to be activated simultaneously. Our data show that bitter molecules inhibit the detection of sugar molecules. This suggests that, in flies, the detection of bitter molecules within mixtures is encoded in two ways: (1) activating bitter-sensitive cells; and (2) inhibiting sugar sensing through the sugar-sensitive cells, thereby making appetitive stimuli less attractive when mixed with bitter substances.

\section{Discussion}

In this work, we evaluated the respective roles of two pathways contributing to the detection of bitter compounds, the activation of bitter-sensitive cells, and the inhibition of sugar detection. The importance of inhibiting sugar detection is exemplified by the observation that flies deprived of bitter-sensitive cells retain the capacity to avoid feeding from sugar solutions containing strychnine almost as well as normal flies. Although the activation of bitter-sensitive cells induce active aversive reactions, such as the $\mathrm{PR}$, sugar-sensing inhibition is very effective in preventing feeding from appetitive solutions when spiked with bitter chemicals. We established that chemicals such as strychnine, lobeline, denatonium, and escin inhibit sugar detection, whereas other chemicals such as L-canavanine, caffeine, and nicotine were not effective at the concentration tested. Given the importance of sugarsensing inhibition, these observations are consistent with former behavioral observations showing that strychnine and lobeline were more potent anti-feedants than caffeine and nicotine in MultiCAFE (Sellier et al., 2011), two-choice assays (Meunier et al., 2003a; Weiss et al., 2011), and a visit-frequency assay (Marella et al., 2006). We further established that mixture suppression by strychnine is dose dependent and reversible and affects sugar detection in each type of sensilla on the proboscis and the legs and that this inhibition is a process affecting specifically the sugar transduction.

Inhibition of sugar detection by bitter chemicals has been described in several animals, including insects, but the extent of this suppression and its role in the feeding behavior has been less characterized. A number of studies described mixture interactions at the periphery using electrophysiology in vertebrates (Formaker et al., 1997; Keast and Breslin, 2002; Frank et al., 2003, 2005; Green et al., 2010) and insects (Chapman, 2003; Meunier et al., 2003a; Moon et al., 2009; Lee et al., 2010; Sellier et al., 2011). The cellular and molecular mechanisms involved in this inhibition have remained elusive so far. Bitter chemicals may directly interact competitively with sugar receptors or with allosteric sites located on them (Xu et al., 2004; Galindo-Cuspinera et al., 2006; Milligan and Smith, 2007; Maillet et al., 2009; Imada et al., 2010) or via direct interaction with transduction cascade elements
(Naim et al., 1994; Talavera et al., 2008) through a rapid entry of amphipathic molecules into taste cells (Peri et al., 2000). In addition, the activation of bitter-sensing cells could laterally inhibit sugar-sensitive cells through neuromodulation as in vertebrates (Roper, 2006; Cao et al., 2009; Dando and Roper, 2009; Herness and Zhao, 2009; Yarmolinsky et al., 2009) or through ephaptic interactions as found recently in insect olfactory sensilla (Su et al., 2012).

Our data establish that sugar-sensing cell inhibition is independent of bitter-cell activation and that this inhibition is specific to sugar detection. First, sugar responses are inhibited by strychnine in all sensilla of the proboscis independently of the presence of bitter-sensing cells in those sensilla. This is the case for l-type sensilla that are not equipped with a bitter-sensitive cell and for i9 sensilla that house only two chemosensory cells, in which the bitter-sensitive cell can be ablated genetically by expressing a toxin in it. Furthermore, if bitter-sensing cells are activated by BL (using ChR2 ectopically expressed in Gr66a cells), the response to sucrose is not affected. This indicates that sugar inhibition can occur in the absence of bitter cells.

Second, sugar-sensitive cells are inhibited by molecules different from those that stimulate bitter-sensitive cells. Strychnine and lobeline (as well as quinine; Sellier et al., 2011) are very potent inhibitors, whereas L-canavanine, caffeine, and nicotine are less effective. This confirms that bitter activation and sugar inhibition are two separate mechanisms, in agreement with the observation that bitter-sensitive gustatory receptors are not expressed in sugar-sensitive cells (Thorne et al., 2004; Marella et al., 2006; Hiroi et al., 2008; Weiss et al., 2011).

Third, when sugar-sensitive cells are activated by BL (using ChR2 ectopically expressed in Gr64f cells), strychnine does not inhibit the response to BL. This indicates that strychnine does not depress the excitability of sugar-sensing cells and suggests that it interferes specifically with sugar reception or transduction pathways. Thus, our data suggest that sugar-sensing cells are equipped with transduction pathways sensitive to bitter chemicals.

Recently, it has been demonstrated that an OBP, OBP49a, is required for sugar inhibition by bitter chemicals (Jeong et al., 2013). OBP49a is expressed by an accessory cell of most gustatory sensilla and is secreted in the sensillum lymph. Its loss results in reduced sugar inhibition or avoidance behavior in the presence of bitter chemicals. OBP49a directly binds quinine and denatonium, both of which are sweet taste inhibitors. Biochemical and genetic evidences show that OBP49a becomes closely associated with the sugar receptor Gr64a, indicating that OBPs may bind bitters and bring them to the immediate proximity of sugar gustatory receptors (Jeong et al., 2013). The presence of OBPs may serve as a mechanism to amplify the sensitivity of sugar neurons by chaperoning the interaction. The authors suggest an alternative mechanism analogous to the OBP LUSH, which activates a pheromone receptor (OR67d) when loaded with the ligand cis-vaccenyl acetate (cVA; Laughlin et al., 2008). However, a recent report suggests that cVA induces olfactory receptor activity in the absence of LUSH (Gomez-Diaz et al., 2013). Our study and findings on gusta- 
tory receptors by Jeong et al. (2013) raise the intriguing possibility that bitter chemicals directly interact with sugar gustatory receptors.

Although sugar-sensing inhibition is an intriguing property of sugar-detecting cells, it also plays a decisive role in allowing flies to avoid mixtures spiked with bitter chemicals. This was very clear when comparing the feeding responses of flies given access to sugar mixed with either strychnine or L-canavanine. Although L-canavanine detection is completely suppressed after Gr66a-cell ablation, strychnine is still detected in these flies. These observations suggest that sugar-sensing inhibition plays a major role in most feeding behavior paradigms used to test feeding activities in flies, including the PER.

PER experiments on flies in which Gr66a cells were ablated or that were expressing ChR2 has allowed us to better understand the interplay of bitter detection and mixture suppression. Control strains, UAS-DTI, and Gr66a-Gal4 flies extend their proboscis less frequently in response to strychnine mixed with sucrose than when strychnine and sucrose were presented on separate legs. Gr66a>DTI flies avoid extending their proboscis in the presence of strychnine and are impaired in retracting their proboscis. L-Canavanine does not inhibit the PER but triggers a subsequent PR that disappears in Gr66a-ablated flies.

In Gr66a $>$ ChR2 flies, the PER is reduced by $\sim 22 \%$ when flies are dually stimulated with sucrose and BL compared with sucrose alone. This level of inhibition is comparable with the responses of flies presented with sucrose and strychnine in the dissociated PER paradigm. The activation of bitter-sensing cells through remote activation or by stimulating with strychnine in Gr66a $>C h R 2$ or Gr64f $>$ ChR2 flies, respectively, triggers the PR (Fig. 4). Our observations are consistent with the hypothesis that the PER is strongly modulated by sugar-sensing inhibition, whereas the PR is triggered through the activation of bitter-sensing cells.

We postulate that sugar inhibition may contribute to adaptation of insects to their environment and should be subjected to selection pressure. One possibility is that sugar-sensing inhibition could be associated with bitter molecules that are particularly toxic for the animals because this mechanism seems to be hardwired, whereas the aversion to bitter chemicals that are detected only by bitter-sensitive cells could be modulated at the level of the synapses by a variety of mechanisms. A partial support to this hypothesis comes from the observation that camphor aversion can be modulated whereas quinine aversion is not in relation to the relative toxicity of these compounds (Zhang et al., 2013).

We speculate that different adaptation strategies may exist across insect species, i.e., the same molecule could activate bitter cells and/or inhibit sugar cells differently. Alkaloids such as strychnine inhibits the detection of sugars in Lepidoptera larvae (Schoonhoven and van Loon, 2002) and sugar alcohols (but not sucrose) in Lymantria dispar (Martin and Shields, 2012). Contrary to Drosophila, the grasshopper Schistocerca americana does not detect L-canavanine by excitation but only by sugar-sensing inhibition (Chapman et al., 1991). In honeybees, sugar-sensing inhibition might be even more developed than bitter detection (de Brito Sanchez, 2011) because honeybees possess very few gustatory receptors.

In summary, our results suggest strongly that detection of noxious compounds involves at least two independent mechanisms: (1) the activation of bitter-sensitive cells; and (2) mixture suppression within sugar-sensitive cells. This inactivation mechanism may contribute to simplify the processing of messages sent to the brain by the taste receptors when confronted with conflicting messages (Fig. 10). Our observations do not challenge the view that taste coding involves labeled lines, but they should cer- tainly encourage us to revise our view of the sensory space encoded by each taste quality.

\section{References}

Bjordal M, Arquier N, Kniazeff J, Pin JP, Léopold P (2014) Sensing of amino acids in a dopaminergic circuitry promotes rejection of an incomplete diet in Drosophila. Cell 156:510-521. CrossRef Medline

Brand AH, Perrimon N (1993) Targeted gene expression as a means of altering cell fates and generating dominant phenotypes. Development 118: 401-415. Medline

Burke CJ, Waddell S (2011) Remembering nutrient quality of sugar in Drosophila. Curr Biol 21:746-750. CrossRef Medline

Cameron P, Hiroi M, Ngai J, Scott K (2010) The molecular basis for water taste in Drosophila. Nature 465:91-95. CrossRef Medline

Cao Y, Zhao FL, Kolli T, Hivley R, Herness S (2009) GABA expression in the mammalian taste bud functions as a route of inhibitory cell-to-cell communication. Proc Natl Acad Sci U S A 106:4006-4011. CrossRef Medline

Chandrashekar J, Hoon MA, Ryba NJP, Zuker CS (2006) The receptors and cells for mammalian taste. Nature 444:288-294. CrossRef Medline

Chapman RF (2003) Contact chemoreception in feeding by phytophagous insects. Annu Rev Entomol 48:455-484. CrossRef Medline

Chapman RF, Ascoli-Christensen A, White PR (1991) Sensory coding for feeding deterrence in the grasshopper Schistocerca americana. J Exp Biol 158:241-259.

Charlu S, Wisotsky Z, Medina A, Dahanukar A (2013) Acid sensing by sweet and bitter taste neurons in Drosophila melanogaster. Nat Commun 4:2042. CrossRef Medline

Chen Y, Amrein H (2014) Enhancing perception of contaminated food through acid-mediated modulation of taste neuron responses. Curr Biol 24:1969-1977. CrossRef Medline

Chen Z, Wang Q, Wang Z (2010) The amiloride-sensitive epithelial $\mathrm{Na}^{+}$ channel PPK28 is essential for Drosophila gustatory water reception. J Neurosci 30:6247-6252. CrossRef Medline

Dahanukar A, Lei YT, Kwon JY, Carlson JR (2007) Two Gr genes underlie sugar reception in Drosophila. Neuron 56:503-516. CrossRef Medline

Dando R, Roper SD (2009) Cell-to-cell communication in intact taste buds through ATP signalling from pannexin 1 gap junction hemichannels. J Physiol 587:5899-5906. CrossRef Medline

de Brito Sanchez MG (2011) Taste perception in honey bees. Chem Senses 36:675-692. CrossRef Medline

Dethier VG (1980) Evolution of receptor sensitivity to secondary plant substances with special reference to deterrents. Am Naturalist 115:45-66. CrossRef

Dethier VG (1987) Discriminative taste inhibitors affecting insects. Chem Senses 12:251-263. CrossRef

Dethier VG, Bowdan E (1989) The effect of alkaloids on sugar receptors and the feeding behaviour of the blowfly. Physiol Entomol 14:127-136. CrossRef

Dethier VG, Bowdan E (1992) Effects of alkaloids on feeding by Phormia regina confirm the critical role of sensory inhibition. Physiol Entomol 17:325-330. CrossRef

Devambez I, Ali Agha M, Mitri C, Bockaert J, Parmentier ML, Marion-Poll F, Grau Y, Soustelle L (2013) $\mathrm{G} \alpha_{\mathrm{o}}$ is required for L-canavanine detection in Drosophila. PLoS One 8:e63484. CrossRef Medline

Dong D, Jones G, Zhang S (2009) Dynamic evolution of bitter taste receptor genes in vertebrates. BMC Evol Biol 9:12. CrossRef Medline

Dus M, Min S, Keene AC, Lee GY, Suh GSB (2011) Taste-independent detection of the caloric content of sugar in Drosophila. Proc Natl Acad Sci U S A 108:11644-11649. CrossRef Medline

Engsontia P, Sangket U, Chotigeat W, Satasook C (2014) Molecular evolution of the odorant and gustatory receptor genes in Lepidopteran insects: implications for their adaptation and speciation. J Mol Evol 79:21-39. CrossRef Medline

Formaker BK, MacKinnon BI, Hettinger TP, Frank ME (1997) Opponent effects of quinine and sucrose on single fiber taste responses of the chorda tympani nerve. Brain Res 772:239-242. CrossRef Medline

Frank ME, Formaker BK, Hettinger TP (2003) Taste responses to mixtures: analytic processing of quality. Behav Neurosci 117:228-235. CrossRef Medline

Frank ME, Formaker BK, Hettinger TP (2005) Peripheral gustatory processing of sweet stimuli by golden hamsters. Brain Res Bull 66:70-84. CrossRef Medline

Fujishiro N, Kijima H, Morita H (1984) Impulse frequency and action potential amplitude in the labellar chemosensory neurones of Drosophila melanogaster. J Insect Physiol 30:317-325. CrossRef 
Fujita M, Tanimura T (2011) Drosophila evaluates and learns the nutritional value of sugars. Curr Biol 21:751-755. CrossRef Medline

Galindo-Cuspinera V, Winnig M, Bufe B, Meyerhof W, Breslin PAS (2006) A TAS1R receptor-based explanation of sweet "water-taste." Nature 441: 354-357. CrossRef

Glendinning JI (1996) Is chemosensory input essential for the rapid rejection of toxic foods? J Exp Biol 199:1523-1534. Medline

Glendinning JI (2002) How do herbivorous insects cope with noxious secondary plant compounds in their diet? Entomol Exp Appl 104:15-25. CrossRef

Glendinning JI (2007) How do predators cope with chemically defended foods? Biol Bull 213:252-266. CrossRef Medline

Gomez-Diaz C, Reina JH, Cambillau C, Benton R (2013) Ligands for pheromone-sensing neurons are not conformationally activated odorant binding proteins. PLoS Biol 11:e1001546. CrossRef Medline

Gordon MD, Scott K (2009) Motor control in a Drosophila taste circuit. Neuron 61:373-384. CrossRef Medline

Green BG, Lim J, Osterhoff F, Blacher K, Nachtigal D (2010) Taste mixture interactions: suppression, additivity, and the predominance of sweetness. Physiol Behav 101:731-737. CrossRef Medline

Gruber F, Knapek S, Fujita M, Matsuo K, Bräcker L, Shinzato N, Siwanowicz I, Tanimura T, Tanimoto H (2013) Suppression of conditioned odor approach by feeding is independent of taste and nutritional value in Drosophila. Curr Biol 23:507-514. CrossRef Medline

Herness S, Zhao FL (2009) The neuropeptides CCK and NPY and the changing view of cell-to-cell communication in the taste bud. Physiol Behav 97:581-591. CrossRef Medline

Hiroi M, Marion-Poll F, Tanimura T (2002) Differentiated response to sugars among labellar chemosensilla in Drosophila. Zool Sci 19:1009-1018. CrossRef Medline

Hiroi M, Meunier N, Marion-Poll F, Tanimura T (2004) Two antagonistic gustatory receptor neurons responding to sweet-salty and bitter taste in Drosophila. J Neurobiol 61:333-342. CrossRef Medline

Hiroi M, Tanimura T, Marion-Poll F (2008) Hedonic taste in Drosophila revealed by olfactory receptors expressed in taste neurons. PLoS One 3:e2610. CrossRef Medline

Hong W, Zhao HB (2014) Vampire bats exhibit evolutionary reduction of bitter taste receptor genes common to other bats. Proc R Soc 281: 20141079. CrossRef

Hornstein NJ, Pulver SR, Griffith LC (2009) Channelrhodopsin2 mediated stimulation of synaptic potentials at Drosophila neuromuscular junctions. J Vis Exp 25:e1133. CrossRef

Imada T, Misaka T, Fujiwara S, Okada S, Fukuda Y, Abe K (2010) Amiloride reduces the sweet taste intensity by inhibiting the human sweet taste receptor. Biochem Biophys Res Commun 397:220-225. CrossRef Medline

Jeong YT, Shim J, Oh SR, Yoon HI, Kim CH, Moon SJ, Montell C (2013) An odorant-binding protein required for suppression of sweet taste by bitter chemicals. Neuron 79:725-737. CrossRef Medline

Jiang P, Josue J, Li X, Glaser D, Li W, Brand JG, Margolskee RF, Reed DR, Beauchamp GK (2012) Major taste loss in carnivorous mammals. Proc Natl Acad Sci U S A 109:4956-4961. CrossRef Medline

Keast SJR, Breslin PAS (2002) An overview of binary taste-taste interactions. Food Qual Prefer 14:111-124.

Kirkness EF, Haas BJ, Sun W, Braig HR, Perotti MA, Clark JM, Lee SH, Robertson HM, Kennedy RC, Elhaik E, Gerlach D, Kriventseva EV, Elsik CG, Graur D, Hill CA, Veenstra JA, Walenz B, Tubío JM, Ribeiro JM, Rozas J, et al. (2010) Genome sequences of the human body louse and its primary endosymbiont provide insights into the permanent parasitic lifestyle. Proc Natl Acad Sci U S A 107:12168-12173. CrossRef Medline

König C, Schleyer M, Leibiger J, El-Keredy A, Gerber B (2014) Bitter-sweet processing in larval Drosophila. Chem Senses 39:489-505. CrossRef Medline

Kool O (2005) Insect antifeedants. Boca Raton, FL: CRC

Laughlin JD, Ha TS, Jones DNM, Smith DP (2008) Activation of pheromone-sensitive neurons is mediated by conformational activation of pheromone-binding protein. Cell 133:1255-1265. CrossRef Medline

Lee Y, Kim SH, Montell C (2010) Avoiding DEET through insect gustatory receptors. Neuron 67:555-561. CrossRef Medline

Lee Y, Kang MJ, Shim J, Cheong CU, Moon SJ, Montell C (2012) Gustatory receptors required for avoiding the insecticide L-canavanine. J Neurosci 32:1429-1435. CrossRef Medline

Li D, Zhang J (2014) Diet shapes the evolution of the vertebrate bitter taste receptor gene repertoire. Mol Biol Evol 31:303-309. CrossRef Medline

Ling F, Dahanukar A, Weiss LA, Kwon JY, Carlson JR (2014) The molecular and cellular basis of taste coding in the legs of Drosophila. J Neurosci 34:7148-7164. CrossRef Medline

Maillet EL, Margolskee RF, Mosinger B (2009) Phenoxy herbicides and fibrates potently inhibit the human chemosensory receptor subunit T1R3. J Med Chem 52:6931-6935. CrossRef Medline

Marella S, Fischler W, Kong P, Asgarian S, Rueckert E, Scott K (2006) Imaging taste responses in the fly brain reveals a functional map of taste category and behavior. Neuron 49:285-295. CrossRef Medline

Marion-Poll F, van der Pers J (1996) Un-filtered recordings from insect taste sensilla. Entomol Exp Appl 80:113-115. CrossRef

Martin TL, Shields VDC (2012) An electrophysiological analysis of the effect of phagostimulant mixtures on the responses of a deterrent-sensitive cell of gypsy moth larvae, Lymantria dispar (L.). Arthrop Plant Interact 6:259-267. CrossRef

Masek P, Scott K (2010) Limited taste discrimination in Drosophila. Proc Natl Acad Sci U S A 107:14833-14838. CrossRef Medline

McBride CS, Arguello JR, O’Meara BC (2007) Five drosophila genomes reveal nonneutral evolution and the signature of host specialization in the chemoreceptor superfamily. Genetics 177:1395-1416. CrossRef Medline

Meunier N, Marion-Poll F, Rospars JP, Tanimura T (2003a) Peripheral coding of bitter taste in Drosophila. J Neurobiol 56:139-152. CrossRef Medline

Meunier N, Marion-Poll F, Lansky P, Rospars JP (2003b) Estimation of the individual firing frequencies of two neurons recorded with a single electrode. Chem Senses 28:671-679. CrossRef Medline

Milligan G, Smith NJ (2007) Allosteric modulation of heterodimeric G-proteincoupled receptors. Trends Pharmacol Sci 28:615-620. CrossRef Medline

Mitri C, Soustelle L, Framery B, Bockaert J, Parmentier ML, Grau Y (2009) Plant insecticide L-canavanine repels Drosophila via the insect orphan GPCR DmX. PLoS Biol 7:e1000147. CrossRef Medline

Moon SJ, Lee Y, Jiao Y, Montell C (2009) A Drosophila gustatory receptor essential for aversive taste and inhibiting male-to-male courtship. Curr Biol 19:1623-1627. CrossRef Medline

Morita H (1959) Initiation of spike potentials in contact chemosensory hairs of insects. III. D.C. stimulation and generator potential of labellar chemoreceptor of Calliphora. J Cell Comp Physiol 54:189-204. CrossRef Medline

Nagel G, Szellas T, Huhn W, Kateriya S, Adeishvili N, Berthold P, Ollig D, Hegemann P, Bamberg E (2003) Channelrhodopsin-2, a directly lightgated cation-selective membrane channel. Proc Natl Acad Sci U S A 100: 13940-13945. CrossRef Medline

Naim M, Seifert R, Nürnberg B, Grünbaum L, Schultz G (1994) Some taste substances are direct activators of G-proteins. Biochem J 297:451-454. Medline

Peri I, Mamrud-Brains H, Rodin S, Krizhanovsky V, Shai Y, Nir S, Naim M (2000) Rapid entry of bitter and sweet tastants into liposomes and taste cells: implications for signal transduction. Am J Physiol Cell Physiol 278:C17-C25. Medline

Rasband WS, Bright DS (1995) NIH Image-a public domain imageprocessing program for the MacIntosh. Microbeam Anal 4:137-149.

Tribolium Genome Sequencing Consortium; Richards S, Gibbs RA, Weinstock GM, Brown SJ, Denell R, Beeman RW, Gibbs R, Beeman RW, Brown SJ, Bucher G, Friedrich M, Grimmelikhuijzen CJ, Klingler M, Lorenzen M, Richards S, Roth S, Schröder R, Tautz D, Zdobnov EM, et al. (2008) The genome of the model beetle and pest Tribolium castaneum. Nature 452:949-955. CrossRef Medline

Roper SD (2006) Cell communication in taste buds. Cell Mol Life Sci 63: 1494-1500. CrossRef Medline

Rosenthal GA (2001) L-Canavanine: a higher plant insecticidal allelochemical. Amino Acids 21:319-330. CrossRef Medline

Schoonhoven LM (1982) Biological aspects of antifeedants. Entomol Exp Appl 31:57-69. CrossRef

Schoonhoven LM, Liner L (1994) Multiple mode of action of the feeding deterrent, toosendanin, on the sense of taste in Pieris brassicae larvae. J Comp Physiol A Neuroethol Sens Neural Behav Physiol 175:519-524.

Schoonhoven LM, van Loon JJA (2002) An inventory of taste in caterpillars: Each species its own key. Acta Zool Acad Scient Hung 48:215-263.

Schroll C, Riemensperger T, Bucher D, Ehmer J, Völler T, Erbguth K, Gerber B, Hendel T, Nagel G, Buchner E, Fiala A (2006) Light-induced activation of distinct modulatory neurons triggers appetitive or aversive learning in Drosophila larvae. Curr Biol 16:1741-1747. CrossRef Medline

Sellier MJ, Marion-Poll F (2011) Mixture interactions in taste sensilla of Drosophila melanogaster. Chem Senses 36:E42-E43.

Sellier MJ, Reeb P, Marion-Poll F (2011) Consumption of bitter alkaloids in Drosophila melanogaster in multiple-choice test conditions. Chem Senses 36:323-334. CrossRef Medline 
Shanbhag SR, Park SK, Pikielny CW, Steinbrecht RA (2001) Gustatory organs of Drosophila melanogaster: fine structure and expression of the putative odorant-binding protein PBPRP2. Cell Tissue Res 304:423-437. CrossRef Medline

Shiraiwa T, Carlson JR (2007) Proboscis extension response (PER) assay in Drosophila. J Vis Exp (3):193. CrossRef

Su CY, Menuz K, Reisert J, Carlson JR (2012) Non-synaptic inhibition between grouped neurons in an olfactory circuit. Nature 492:66-71. CrossRef Medline

Swarup S, Morozova TV, Sridhar S, Nokes M, Anholt RRH (2014) Modulation of feeding behavior by odorant-binding proteins in Drosophila melanogaster. Chem Senses 39:125-132. CrossRef Medline

Sweeney ST, Broadie K, Keane J, Niemann H, O’Kane CJ (1995) Targeted expression of tetanus toxin light chain in Drosophila specifically eliminates synaptic transmission and causes behavioral defects. Neuron 14: 341-351. CrossRef Medline

Talavera K, Yasumatsu K, Yoshida R, Margolskee RF, Voets T, Ninomiya Y, Nilius B (2008) The taste transduction channel TRPM5 is a locus for bitter-sweet taste interactions. FASEB J 22:1343-1355. CrossRef Medline

Thistle R, Cameron P, Ghorayshi A, Dennison L, Scott K (2012) Contact chemoreceptors mediate male-male repulsion and male-female attraction during Drosophila courtship. Cell 149:1140-1151. CrossRef Medline

Thorne N, Chromey C, Bray S, Amrein H (2004) Taste perception and coding in Drosophila. Curr Biol 14:1065-1079. CrossRef Medline

Wang Z, Singhvi A, Kong P, Scott K (2004) Taste representations in the Drosophila brain. Cell 117:981-991. CrossRef Medline
Wanner KW, Robertson HM (2008) The gustatory receptor family in the silkworm moth Bombyx mori is characterized by a large expansion of a single lineage of putative bitter receptors. Insect Mol Biol 17:621-629. CrossRef Medline

Weiss LA, Dahanukar A, Kwon JY, Banerjee D, Carlson JR (2011) The molecular and cellular basis of bitter taste in Drosophila. Neuron 69:258-272. CrossRef Medline

Wieczorek H, Wolff G (1989) The labellar sugar receptor of Drosophila. J Comp Physiol A Neuroethol Sens Neural Behav Physiol 164:825-834. CrossRef

Wooding S (2005) Evolution: a study in bad taste? Curr Biol 15:R805-R807. CrossRef Medline

Wright GA, Mustard JA, Simcock NK, Ross-Taylor AAR, McNicholas LD, Popescu A, Marion-Poll F (2010) Parallel reinforcement pathways for conditioned food aversions in the honeybee. Curr Biol 20:2234-2240. CrossRef Medline

Xu H, Staszewski L, Tang H, Adler E, Zoller M, Li X (2004) Different functional roles of T1R subunits in the heteromeric taste receptors. Proc Natl Acad Sci U S A 101:14258-14263. CrossRef Medline

Yarmolinsky DA, Zuker CS, Ryba NJP (2009) Common sense about taste: from mammals to insects. Cell 139:234-244. CrossRef Medline

Zhang YV, Raghuwanshi RP, Shen WL, Montell C (2013) Food experienceinduced taste desensitization modulated by the Drosophila TRPL channel. Nat Neurosci 16:1468-1476. CrossRef Medline

Zhao GQ, Zhang Y, Hoon MA, Chandrashekar J, Erlenbach I, Ryba NJ, Zuker CS (2003) The receptors for mammalian sweet and umami taste. Cell 115:255-266. CrossRef Medline 